\title{
Quantization Effects in TanDEM-X Data
}

\author{
Michele Martone, Benjamin Bräutigam, and Gerhard Krieger, Fellow, IEEE
}

\begin{abstract}
TerraSAR-X add-on for Digital Elevation Measurement (TanDEM-X) is an innovative spaceborne bistatic SAR system comprising the twin satellites TerraSAR-X and TanDEM-X (TSX and TDX, respectively). The primary objective of the mission is the generation of a worldwide, timely, and consistent digital elevation model (DEM) in a bistatic synthetic aperture radar (SAR) configuration with unprecedented accuracy. For TanDEM-X and for future spaceborne SAR missions, an increasing volume of onboard data is going to be demanded. This is due to the employment of large bandwidths, high pulse repetition frequencies, and multiple polarizations, which implies inevitably hard requirements in terms of onboard memory and downlink capacity. In this scenario, SAR raw data quantization represents an essential aspect. The data rate employed for the digitization of the recorded radar signal affects both the amount of data to be stored and transmitted to the ground and the quality of the resulting SAR products. In this paper, the impact of quantization on TanDEM-X monostatic and interferometric data is evaluated. Key quantities in estimating interferometric and SAR performance, such as coherence and phase errors, are investigated in detail. Based on the obtained results, an optimization of the resource-allocation strategy for the global DEM acquisition of TanDEM-X is discussed.
\end{abstract}

Index Terms-Block-adaptive quantization (BAQ), SAR interferometry (InSAR), synthetic aperture radar (SAR), TerraSAR-X add-on for Digital Elevation Measurement (TanDEM-X) mission.

\section{INTRODUCTION}

$\mathbf{S}$ YNTHETIC aperture radar interforometry (InSAR) represents a well-recognized technique for many remote sensing applications. About three decades of research studies, technical progress, and development in the field have demonstrated the potential of spaceborne InSAR systems for the assessment and monitoring of many geophysical parameters, such as ground deformations, ocean currents, and Earth's topography by generation of digital elevation models (DEMs). In 2000, the Shuttle Radar Topography Mission created the first elevation data on a nearly global scale, limited to a latitude range from $56^{\circ} \mathrm{S}$ to $60^{\circ} \mathrm{N}$ [1]. Ten years later, the TerraSAR-X add-on for Digital Elevation Measurement (TanDEM-X) mission has opened a new era in spaceborne radar remote sensing. Developed under a public-private partnership between the German Aerospace Center (DLR) and Astrium GmbH [2], [3], the TerraSAR-X SAR satellite (TSX, launched in 2007) is enhanced by its twin radar satellite TanDEM-X (TDX, launched in 2010). The two satellites fly in a closely controlled formation with typical

Manuscript received August 6, 2013; revised December 14, 2013 and April 2, 2014; accepted April 29, 2014. This work was supported in part by the German Federal Ministry for Economic Affairs and Energy under Grant Förderkennzeichen 50 EE 1035.

The authors are with the Microwaves and Radar Institute, German Aerospace Center (DLR), 82234 Wessling, Germany.

Color versions of one or more of the figures in this paper are available online at http://ieeexplore.ieee.org.

Digital Object Identifier 10.1109/TGRS.2014.2325976
TABLE I

SYSTEM PARAMETERS FOR THE TDX MISSION

\begin{tabular}{|l|l|}
\hline Parameter & Value \\
\hline Satellite Height (equator) & $514 \mathrm{~km}$ \\
\hline Carrier Frequency & $9.65 \mathrm{GHz}$ \\
\hline Radar Wavelength & $3.11 \mathrm{~cm}$ \\
\hline Chirp Bandwidth & $100 \mathrm{MHz}$ \\
\hline Chirp Length & $10-60 \mu \mathrm{s}$ \\
\hline Antenna Length & $4.8 \mathrm{~m} \mathrm{(azimuth),0.8} \mathrm{m} \mathrm{(elevation)}$ \\
\hline Incidence Angles & $29^{\circ}-48^{\circ}$ \\
\hline Nominal Available BAQ Rates & $2,3,4,6,8$ bits/sample \\
\hline Satellite Memory & TSX: 256 Gbit, TDX: 512 Gbit \\
\hline Downlink Capacity & $\sim 260 \mathrm{Mbits} / \mathrm{s}$ (total net data rate) \\
\hline
\end{tabular}

distances between 250 and $500 \mathrm{~m}$. They act as a large singlepass radar interferometer with the opportunity of flexible baseline selection for the demonstration of new SAR techniques. By this, TanDEM-X provides the community with a unique data set to be exploited for a broad range of commercial and scientific applications. The primary objective of the mission is to generate a worldwide, consistent, timely, and high-precision DEM [2]. Up to July 2013, TanDEM-X has completed the acquisition of two global mappings of the Earth's landmass in bistatic SAR acquisition mode, where either TSX or TDX is used as a transmitter (master) and both satellites (master and slave) record simultaneously the signal scattered back from the Earth's surface. For the two global DEM acquisitions, different baselines and mutually displaced beams are employed to improve the performance and to keep it almost uniform over the range [2]. A list of TanDEM-X system parameters, to which we will refer in this paper, is given in Table I.

The next big challenge to be addressed by future spaceborne remote sensing missions is now turning to the estimation and long-term monitoring of dynamic processes in the Earth's environmental system, such as deformation events, forest height and biomass change, ice/glacier velocity fields, and ocean surface currents. DLR is therefore investigating an innovative singlepass interferometric and fully polarimetric L-band radar mission (Tandem-L) [4], which exploits innovative high-resolution wide-swath SAR modes, together with the use of large bandwidths, high pulse repetition frequencies, and multiple acquisition channels [5]. Definitely, this is associated with the clear demand of gathering an increasing amount of information in a shorter time interval, which implies, from mission design, harder requirements in terms of onboard memory and downlink capacity.

In this scenario, SAR raw data quantization represents an aspect of primary importance since the data rate employed to digitize the recorded radar signal, on one hand, defines the amount of data to be collected and transmitted to the ground and, on the other hand, directly affects the performance of the SAR products. The main focus of this paper is therefore 
to evaluate and assess quantitatively the impact of raw data quantization on SAR imaging and interferometric performance using bistatic TanDEM-X experimental data. In the following section, the quantization technique employed on the TSX and TDX satellites [the block adaptive quantization (BAQ)] and the quantization errors affecting the SAR performance are shortly recalled, and the investigation approach based on the present analyses is shown. In Section III, the impact of raw data quantization is evaluated on key parameters in estimating interferometric and SAR performance, such as the noise-equivalent sigma zero (NESZ), the interferometric coherence, the interferometric phase errors, and the relative height accuracy of a DEM. Quantization effects in the presence of inhomogeneity in the backscatter response and for different terrain characteristics are investigated as well. Based on the obtained results, the resource-allocation strategy for the global DEM acquisition of TanDEM-X has been consequently adapted, in order to improve the overall DEM performance (see Section IV). This paper is concluded in Section V with a summary and outlook.

\section{SAR RAW DATA QUANTIZATION: BACKGROUND}

\section{A. Block Adaptive Quantization}

On the TSX and TDX satellites, the received backscattered signal is first digitized by an 8-bit analog-to-digital converter (ADC) and then further compressed by a block-adaptive quantizer. BAQ is a lossy data reduction technique (i.e., the data reconstructed after decompression are a distorted version of the original input samples) that uses local statistics of raw data blocks in order to set the requantization decision levels. A space-varying estimation of raw data statistics is performed for each block of the input data (for TSX and TDX, the raw data blocks have a fixed size of 128 samples, separately, for the inphase and quadrature channels). This information is then used to determine the quantization decision levels that best match with the observed statistics [6], [7]. BAQ is nowadays one of the most widely recognized methods for raw data compression as it represents a good compromise between scheme complexity (a simple scalar quantization algorithm), granted image quality, and achievable compression ratio. Therefore, BAQ is an attractive solution for spaceborne SAR systems, where a huge amount of onboard data needs to be stored and then transmitted to the ground. In the last years, novel quantization algorithms have been proposed to allow finer performance and resource optimization, by implementing noninteger compression rates [8]-[11]. On TSX and TDX, possible compression rates are $8: 2,8: 3,8: 4,8: 6$, and $8: 8$, where the latter corresponds to BAQ bypass [12], [13]. The compression rate is individually configured before every data take by instrument commanding and is kept constant for the whole acquisition.

\section{B. Quantization Errors and Low Scattering Suppression}

Generally, quantization errors are mainly given by the sum of two contributions: granular noise and overload noise. The former is due to the reduced number of output decision levels within the supported range, where the latter is introduced by

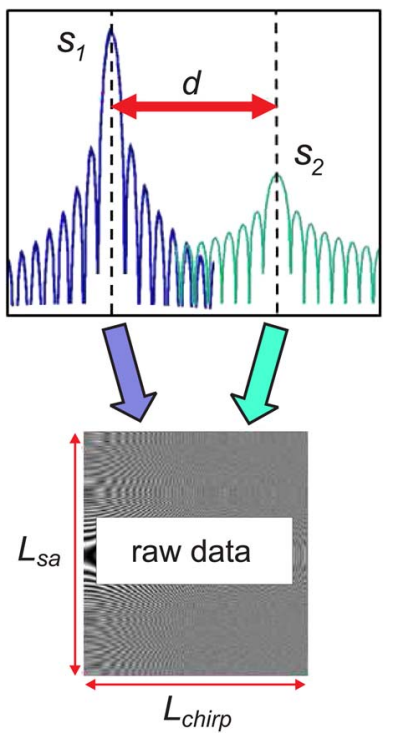

Fig. 1. Impulse response of the two point scatterers $s_{1}$ and $s_{2}$ overlaps in the raw data domain if both the azimuth and range distances $d_{\mathrm{az}}$ and $d_{\mathrm{rg}}$ are small with respect to synthetic antenna length $L_{\mathrm{sa}}$ and chirp length $L_{\text {chirp }}$, respectively [see also (1) and (2)].

the clipping of input signals exceeding the supported range. If the bits employed for data compression are fewer, then the quantization noise power affecting the SAR image quality is higher. For the TSX and TDX cases, the granular noise can be considered the dominant error source since the instrument parameters are set to minimize the occurrence of saturation effects in the raw data. In [12], the overflow (i.e., clipping) rate occurring in the raw data is investigated for the TSX satellite. In the study, several hundreds of data takes are considered, and each one is divided into raw data blocks. It is verified that, in more than $99 \%$ of the blocks, clipping below $1 \%$ occurs (and only $0.2 \%$ of the blocks have a clipping above 3\%, which is considered a critical threshold). Similar results have been obtained for the TDX satellite from analyses conducted during the TDX commissioning phase, few months after its launch. Moreover, in [2] it is demonstrated that the performance loss due to raw data digitization within TanDEM-X, resulting from the quantization process, matches quite well with the theoretic predictions for an optimum uniform Cartesian quantizer (i.e., where no clipping effects exist).

On the other hand, inhomogeneity in the SAR backscatter distribution causes further signal-dependent performance degradation. This is the case, for example, of urban areas, where a high dynamic range in backscatter can be expected. Such an effect is called low scattering suppression [14]; it is peculiar to the SAR acquisition principle and has to be considered an additional quantization error source, different from granular and clipping noise, since it is visible only after SAR processing. In Fig. 1, two targets, i.e., $s_{1}$ and $s_{2}$, with different magnitude response are depicted. Their responses overlap in the raw data domain if both the azimuth and range distances $d_{\mathrm{az}}$ and $d_{\mathrm{rg}}$ are small with respect to synthetic antenna length $L_{\mathrm{sa}}$ and chirp length $L_{\text {chirp }}$, respectively, i.e.,

$$
d_{\mathrm{az}} \ll L_{\mathrm{sa}}=\lambda \frac{r}{L}
$$




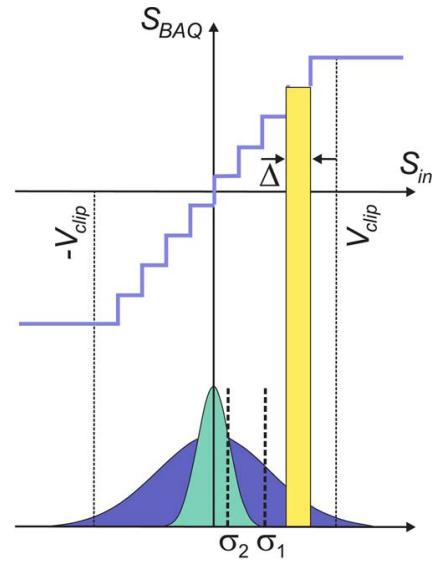

Fig. 2. (Bottom) Probability density functions for the two targets of Fig. 1 are sketched with different colors. According to the BAQ algorithm, the decision levels $\Delta$ and the clipping thresholds for the quantization process $\pm V_{\text {clip }}$ are set as a function of the mean power of the raw data block, which is mostly determined by $s_{1}$ (in this example, $\sigma_{1} \gg \sigma_{2}$ ). Therefore, if two overlapping targets have different power responses, the strong signal is better reconstructed, whereas the low one $\left(s_{2}\right)$ is heavily distorted.

$$
d_{\mathrm{rg}} \ll L_{\mathrm{chirp}}=\frac{c \tau_{p}}{2 \sin \left(\theta_{i}\right)}
$$

where $c$ is the speed of light, $\tau_{p}$ is the pulse duration, $\theta_{i}$ is the incidence angle, $\lambda$ is the radar wavelength, $r$ is the slant range, and $L$ is the antenna length in azimuth. For TSX and TDX, typical values of $L_{\mathrm{sa}}$ and $L_{\mathrm{chirp}}$ are on the order of a few kilometers. The decision levels and the clipping thresholds for the compression are determined according to the mean power of the raw data block, as shown in Fig. 2. Therefore, if two overlapping targets have different magnitude responses, the strong signal is better reconstructed, whereas the low one is heavily distorted. To quantify the described effect, simulations of two 1-D azimuth-compressed point targets have been carried out. The power of the strong target $P_{s}$ is kept constant, whereas the power of the low one $P_{l}$ is varying, to evaluate the distortion for different power ratios of the two. The targets are located at a distance of about $50 \mathrm{~m}$ in azimuth, in order to ensure sufficient overlapping of the raw data responses. The resulting performance degradation is shown in Fig. 3, where the phase error is plotted for the available BAQ rates and along the power ratio $P_{\text {ratio }}$, i.e.,

$$
P_{\text {ratio }}=\frac{P_{s}}{P_{l}}
$$

The phase error corresponds to the phase difference with reference to the bypass case evaluated at the peak of the compressed target with lower amplitude. It strongly depends on the power ratio of the two targets and, at the same time, on the quantization rate employed for compression. While, for the case of 6 bits/sample, almost no degradation is observed (less than $1^{\circ}$ ), a sensitive performance loss is shown when reducing the quantization rate to 2 bits/sample, for which a phase error of about $14^{\circ}$ (for a power ratio of $15 \mathrm{~dB}$ ) is obtained. The phase error has been evaluated also for the strong magnitude target and, as expected, found to be independent of the power ratio (the dependence on the quantization ratio, of course, remains).

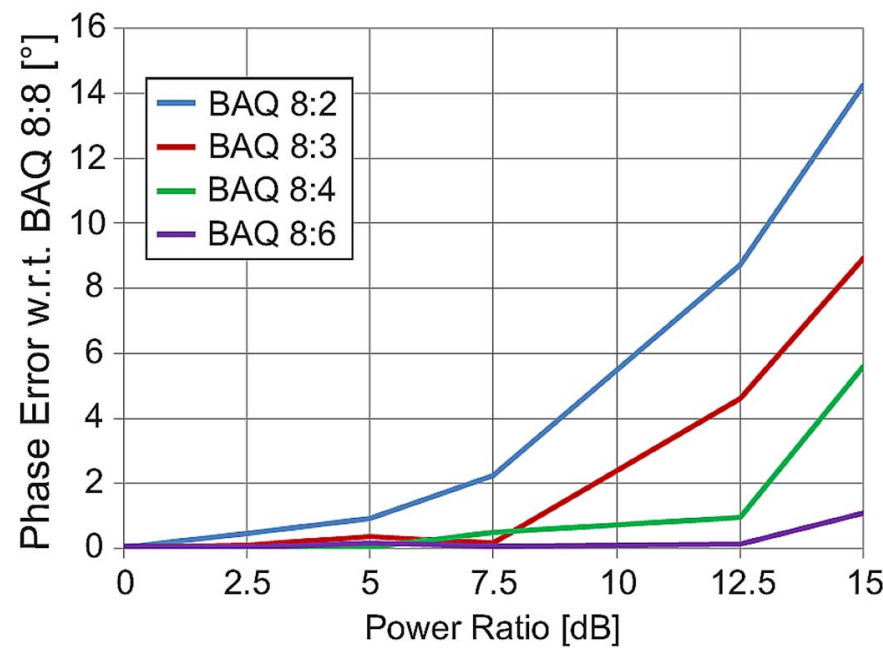

Fig. 3. Low scattering suppression effects are evaluated by means of simulations of two azimuth-compressed point targets. The power of the strong target is kept constant, whereas the power of the low one is varying. The targets are located at a distance of about $50 \mathrm{~m}$ in azimuth, in order to ensure sufficient overlapping of the raw data responses. The phase error (with reference to the bypass case) is evaluated at the peak of the compressed target with lower amplitude and is plotted for the available BAQ rates and along the power ratio, as expressed in (3).

Based on the present investigations, we can conclude that, in the most general case, quantization errors are to be treated as a nonlinear and signal-dependent error source affecting the SAR data, for which the correlation between noise and data can no longer be neglected. The impact of the described low scattering suppression [14] on several SAR performance descriptors is discussed in Section III.

\section{Investigation Approach}

The steps to evaluate quantization effects on TDX data are shown in Fig. 4. Bistatic acquisitions are commanded with BAQ bypass in both SAR instruments. The recorded SAR raw data are compressed on ground into multiple data sets using all available BAQ rates. The employment of different BAQ settings for the two satellites (e.g., TSX 8:4/TDX 8:3) allows to further refine the granularity of the achievable performance, and this has been investigated as well. The obtained raw data products are then processed into SAR images, with a groundrange resolution of about $3 \mathrm{~m}$. From these, interferograms, coherence maps, and DEMs are derived. The interferometric products have a final ground-range resolution of approximately $12 \mathrm{~m}$, obtained by applying a multilook filtering to the bistatic interferogram. The total number of independent looks $N_{l}$ is mostly between 16 and 32, depending on the incidence angle (specified in Table I) and on the processed bandwidths [2]. Each scene extends typically by $30 \mathrm{~km}$ in range and $50 \mathrm{~km}$ in azimuth. The SAR processing is performed by the interferometric TanDEM-X processor [15], providing the most accurate and reliable output data comparable to the operational DEM acquisitions. By reprocessing the same data acquisitions with different BAQ rates, it is possible to isolate the quantization effects from other error sources. For the present investigations, dedicated acquisitions were carried out on defined test sites 


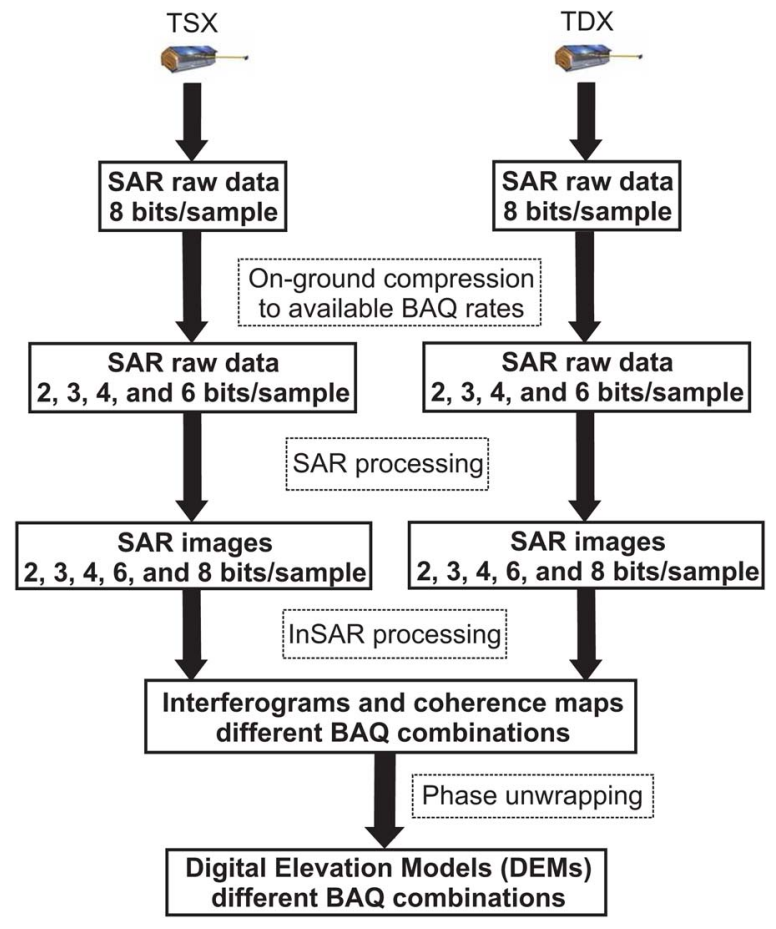

Fig. 4. Workflow for test data acquisition, on-ground quantization, and processing. Raw data commanded with BAQ bypass are compressed on ground into multiple data sets using all available quantization rates. The products obtained are then processed into SAR images, from which interferograms, coherence maps, and DEMs are derived.

TABLE II

Test Sites for Quantization Analysis. For Each Test Site, Bistatic ACQUisitions HaVe BeEn COMMANDED With BAQ BYPASS IN BOTH SAR INSTRUMENTS

\begin{tabular}{|l|l|l|}
\hline Test Site & Land Cover & {$[$ Lat./Lon.] } \\
\hline 1. Salar de Uyuni (Bolivia) & Salt Lake & {$\left[20^{\circ} \mathrm{S}, 67^{\circ} \mathrm{W}\right]$} \\
\hline 2. Amazon Forest 1 (Brazil) & Rainforest & {$\left[4^{\circ} \mathrm{S}, 64^{\circ} \mathrm{W}\right]$} \\
\hline 3. Amazon Forest 2 (Brazil) & Rainforest & {$\left[7^{\circ} \mathrm{S}, 66^{\circ} \mathrm{W}\right]$} \\
\hline 4. Amazon Forest 3 (Brazil) & Rainforest & {$\left[6^{\circ} \mathrm{S}, 63^{\circ} \mathrm{W}\right]$} \\
\hline 5. Greenland & Ice and Snow & {$\left[71^{\circ} \mathrm{N}, 42^{\circ} \mathrm{W}\right]$} \\
\hline 6. Antarctica & Ice and Snow & {$\left[74^{\circ} \mathrm{S}, 10^{\circ} \mathrm{W}\right]$} \\
\hline 7. Las Vegas & Urban Area & {$\left[36^{\circ} \mathrm{N}, 115^{\circ} \mathrm{W}\right]$} \\
\hline 8. Mexico City & Urban Area & {$\left[19^{\circ} \mathrm{N}, 99^{\circ} \mathrm{W}\right]$} \\
\hline 9. Borneo Forest (Indonesia) & Tropical Forest & {$\left[-3^{\circ}, 0^{\circ}\right]$} \\
\hline 10. Appalachian (USA) & Mountainous Forest & {$\left[35^{\circ} \mathrm{N}, 82^{\circ} \mathrm{E}\right]$} \\
\hline 11. Death Valley (USA) & Soil and Rocks & {$\left[41^{\circ} \mathrm{N}, 119^{\circ} \mathrm{W}\right]$} \\
\hline 12. Taklamakan Desert (China) & Sandy Desert & {$\left[39^{\circ} \mathrm{N}, 82^{\circ} \mathrm{E}\right]$} \\
\hline 13. Iowa (USA) & Agricultural Area & {$\left[41^{\circ} \mathrm{N}, 93^{\circ} \mathrm{W}\right]$} \\
\hline
\end{tabular}

showing different land cover types and topography characteristics, which are listed in Table II. From each of these sites, up to six product sets, obtained from different compression rates, were available for performance comparison.

\section{Performance Analysis}

In this section, the performance impact of different raw data quantization rates on TanDEM-X data is presented. As key SAR parameters, the NESZ (see Section III-A), the interferometric coherence (see Section III-B), phase errors (see Section III-C), and DEM relative height accuracy (see Section III-D) are investigated.
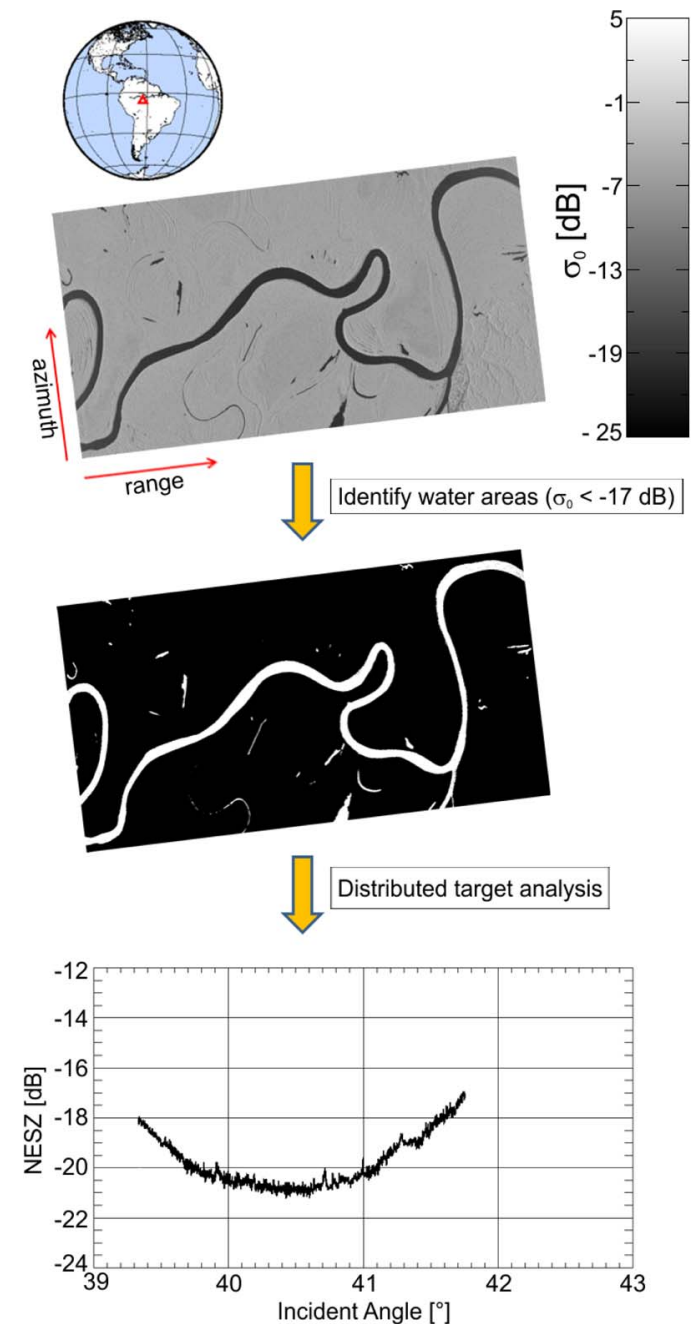

Fig. 5. Steps followed for NESZ estimation. The test site is located in the Amazon rainforest and is crossed by one river, entirely from near to far range. A threshold of about $-17 \mathrm{~dB}$ (slightly adapted for each scene) is applied to locate flat water areas to be considered for the distributed target analysis. The corresponding pixels are depicted in white in the mask in the middle. The NESZ profile curves are finally derived by averaging the valid pixels along the azimuth.

\section{A. NESZ}

NESZ is a measure of the system sensitivity to areas with low radar backscatter. It is given by the value of the backscatter coefficient corresponding to SNR equal to one and includes all error contributions induced by the system, such as antenna pattern, instrument thermal noise, and processing filters [16]. In order to quantitatively estimate the noise power affecting TSX and TDX SAR products, a distributed target analysis over regions with very low backscatter has been carried out. In particular, areas covered by flat water almost completely reflect the radar signal to specular direction. It can be therefore assumed that the signal received by the antenna over such low backscatter areas is below the system noise. The procedure adopted for NESZ estimation is shown in Fig. 5. The test area in the figure is located in the Amazon Rainforest and is crossed by one river entirely from near to far range. Forested areas have been filtered out and are represented in black in the mask in the middle. Then, the valid pixels (white areas in the mask, where 

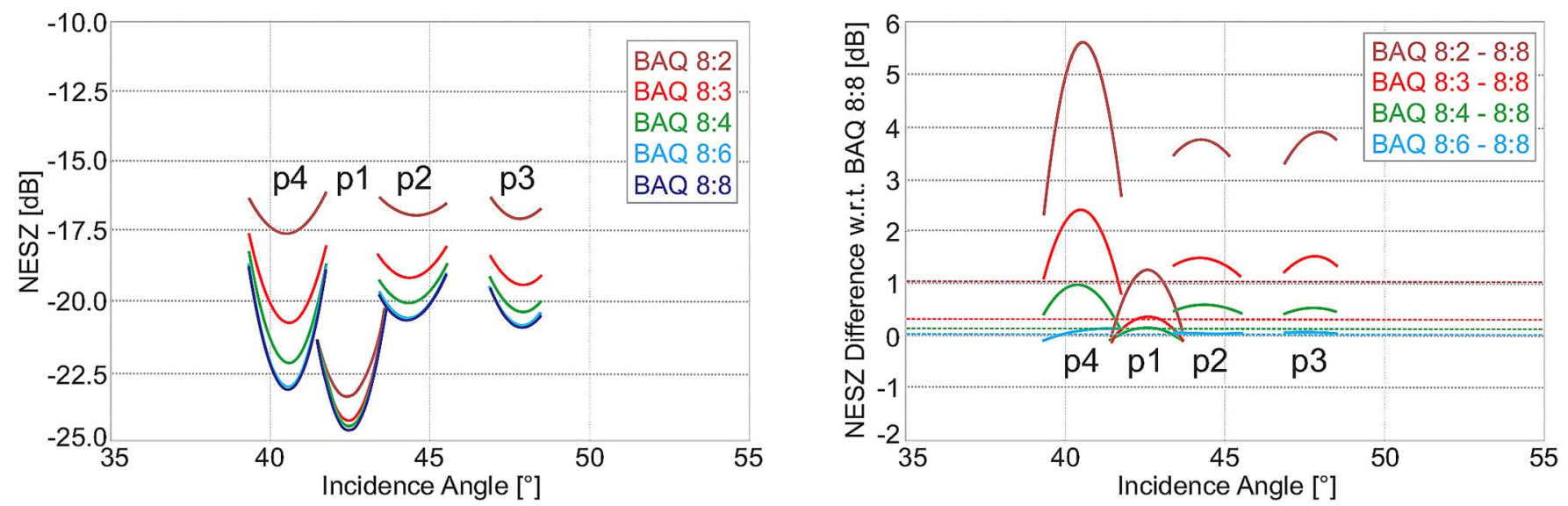

Fig. 6. (Left) NESZ over incidence angle for different BAQ rates (depicted with different colors) and four different data acquisitions, derived as explained in Fig. 5. The highest and lowest curves indicate the NESZ for the case of BAQ 8:2 and BAQ bypass, respectively. (Right) NESZ degradation introduced by quantization with respect to the bypass case. The theoretical degradation has been derived for the different quantization rates, according to [13], and is represented by the horizontal lines. Only the profile "p1" matches quite well with the theoretical predictions (see also Fig. 7).

$\left.\sigma_{0}<-17 \mathrm{~dB}\right)$ are averaged along the azimuth direction, and an additional condition on the median of each estimation patch $(11 \times 11$ pixels $)$ is applied in order to consider only homogeneous and flat water areas, to finally derive the corresponding NESZ profile (at the bottom of Fig. 5). For the present analysis, incidence angles from $39^{\circ}$ to $48^{\circ}$ have been investigated over different test areas, and the NESZ has been estimated for the master satellite (for TSX and TDX, the observed difference in terms of NESZ is usually less than $1 \mathrm{~dB}$ [17], [18]). The NESZ profile curves, resulting from an interpolation along range of the measured values, are depicted on the left-hand side of Fig. 6 for each quantization rate of four different data acquisitions over the salt lake of Uyuni (Bolivia) and over the Amazon rainforest, corresponding to the test sites 1, 2, 3, and 4 of Table II (the respective NESZ profiles in Fig. 6 are numbered accordingly).

In order to validate the present results, they have been compared with the NESZ degradation estimated adopting the theoretical model presented in [13], where a performance analysis of BAQ is carried out by simulating the complete system and signal models for the TSX and TDX satellites. The SNR at the output of the BAQ block $\mathrm{SNR}_{\text {baq }}$ is related to the one calculated at the system input $\mathrm{SNR}_{\mathrm{in}}$, i.e.,

$$
\mathrm{SNR}_{\mathrm{baq}}=\frac{\mathrm{SNR}_{\mathrm{in}}}{1+\frac{E\left\{|q(t)|^{2}\right\}}{A^{2} E\left\{|n(t)|^{2}\right\}}}
$$

where $n(t)$ is the receiver noise, $A$ is the scaling factor peculiar to the quantization process [13], $q(t)$ is the quantization noise, and $E\{\cdot\}$ indicates statistical average. The degradation due to quantization is derived as a function of $\mathrm{SNR}_{\mathrm{in}}$ and of the signal-to-clipping ratio $\gamma_{\text {clip }}$, which gives information about the amount of overload at the input of the quantizer. It is demonstrated that, for $\gamma_{\text {clip }}$ higher than a certain threshold, the saturation noise becomes dominant and has, in general, a more severe influence than the granular noise. For this reason, on the TSX and TDX satellites, the receiver gain is set in order to prevent the occurrence of saturation effects [12]. According to the NESZ definition, the quantization effects are evaluated by considering the degradation of $\mathrm{SNR}_{\mathrm{baq}}$ for the particular case of $\mathrm{SNR}_{\text {in }}=1$ (which is kept constant and homogeneous in the simulations).

On the right-hand side of Fig. 6, the NESZ difference with respect to the bypass case is shown (for each data take, all the other acquisition and processing parameters are the same), and the NESZ degradation with reference to BAQ 8:8 obtained by simulations is indicated with horizontal lines depicted with different colors, each one representing the compression rate indicated in the figure legend. A general underestimation of the employed model appears evident, except for the profile "p1". In order to understand better the observed discrepancy, the backscatter distribution of the considered scenes has to be inspected. A representative scene, from which the profiles "p2", "p3", and "p4" are derived, is depicted in Fig. 5. Here, the rivers considered for NESZ estimation are usually not more than a few hundred meters wide, about one order of magnitude smaller than the typical synthetic antenna and the chirp length for TSX and TDX. Therefore, the responses from the close and stronger backscatter area (such as forest, soil and rocks) overlap considerably with the ones coming from the water area, and the consequent setting of the quantization decision levels is biased by the strong target responses, leading to a suppression of the low backscatter region (as explained in Section II-B). This results in an increase in the noise floor (i.e., of the NESZ degradation), which becomes more evident when fewer bits are employed for quantization, and it explains the observed inconsistency with the simulation results, where a uniform and homogeneous backscatter response was considered. Indeed, the performance resulting from BAQ with 6 and 8 bits/sample is practically the same for all the analyzed test sites and in good agreement with the simulation results, whereas a substantial degradation in terms of radiometric accuracy up to $6 \mathrm{~dB}$ is observed for the profiles "p2", "p3", and "p4" when employing 2 bits/sample, which is due to the described low scattering suppression effect. Even if we would allow to save $75 \%$ of the memory required for one acquisition, such a configuration setting causes a noticeable loss in the SAR image quality and should be avoided when possible. On the other hand, the SAR 


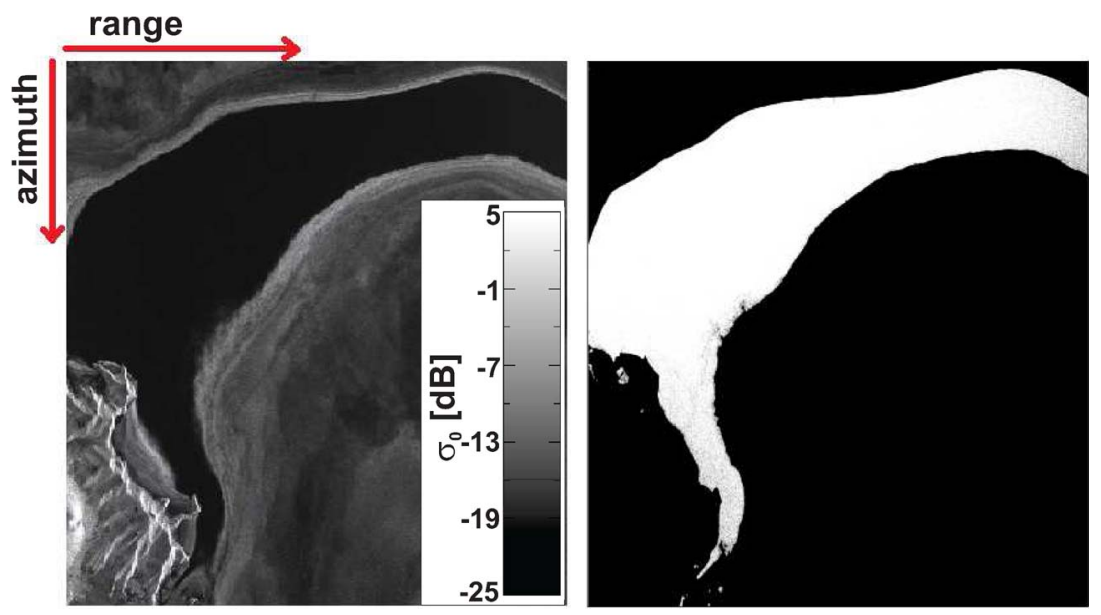

Fig. 7. (Left) SAR amplitude of the salt lake of Uyuni. (Right) Mask used for NESZ estimation. The low backscatter area is highlighted in white and is probably due to wet conditions of the soil. It extends by about $4 \mathrm{~km}$ along the azimuth direction (which is comparable to the synthetic antenna length), and entirely from near to far range. It can be therefore assumed that the quantization decision levels in the low backscatter area are less influenced by the adjacent high backscatter areas. The resulting NESZ degradation corresponds to the profile "p1" in Fig. 6 and agrees quite well with the simulation results [13].
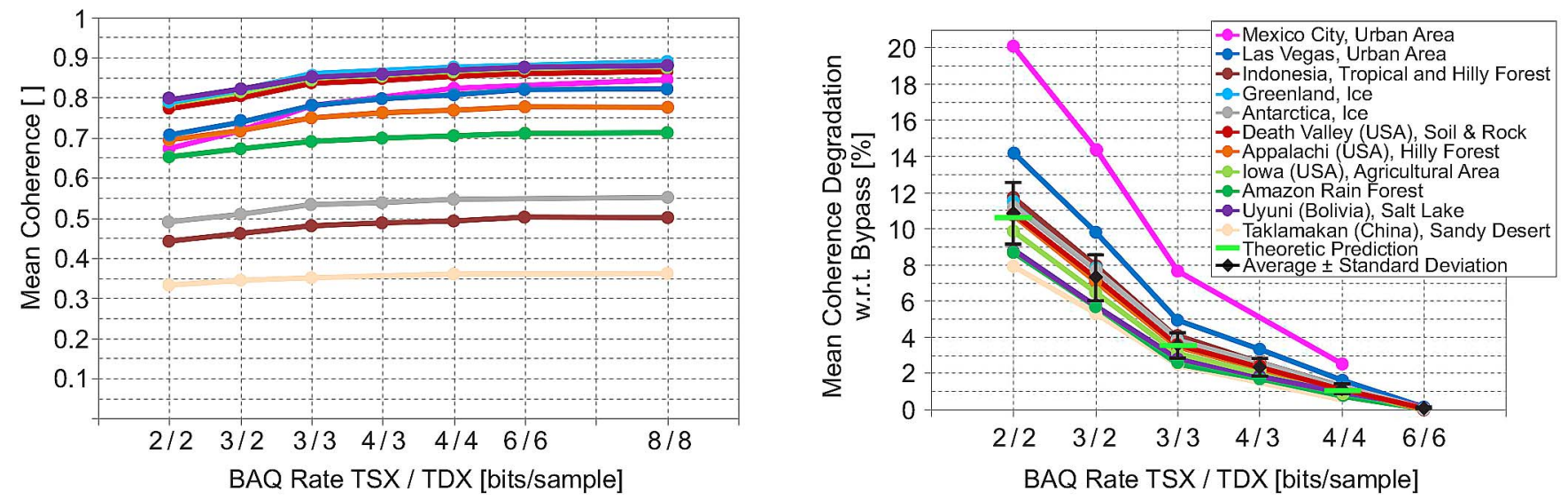

Fig. 8. (Left) Interferometric coherence over BAQ rates for different test sites (depicted with different colors). (Right) Coherence degradation with respect to the bypass case, for different test sites (depicted with different colors). Different BAQ settings for the two satellites (e.g., TSX 8:4/TDX 8:3) are also investigated. The black bars in the right plot represent the average and the standard deviation of the estimated degradations for each BAQ rate, and the short horizontal green lines indicate the theoretic prediction for the cases of 2,3, and 4 bits/sample, as derived in [2]. Each curve corresponds to one acquisition compressed and reprocessed for different BAQ rates.

image, from which the profile "p1" is derived, is shown in Fig. 7. It is located in the salt lake of Uyuni (test site 1 in Table II), and low backscatter probably due to wet conditions of the soil is observed on an area extending by about $4 \mathrm{~km}$ along azimuth, which is comparable to the synthetic antenna length. Therefore, the setting of the quantization decision levels over the salt lake is on average little influenced by the neighboring high backscatter areas. The resulting NESZ degradation of "p1" matches quite well with the theoretic predictions. Therefore, the backscatter characteristics of the imaged scene strongly impact the sensitivity of a SAR system, particularly when low BAQ rates are used, an aspect which needs to be strictly taken into account for performance definition and design.

\section{B. Interferometric Coherence}

The key quantity to evaluate the quality of InSAR products is the interferometric coherence. It represents the normalized correlation coefficient between master (monostatic channel) and slave (bistatic channel) acquisitions, and its absolute value gives information about the amount of noise in the interferogram. Several error sources contribute to coherence loss in bistatic TDX data [19]. A multilooking processing is applied to the original SAR images, so that the interferometric coherence maps have a final ground-range resolution of about $12 \mathrm{~m}$. (The corresponding number of looks varies from 16 to 32 looks.) Areas showing different land cover characteristics have been acquired with different polarizations, incidence angles, and baselines (corresponding to the test sites 1, 2, and 5-13 of Table II). For each scene, the mean coherence over land has been evaluated by applying a water mask.

On the left-hand side of Fig. 8 the interferometric coherence is depicted for the analyzed scenes and BAQ rates. As expected, if fewer bits are employed for quantization, then lower coherence is observed for the same test site. The results plotted in Fig. 8 are determined for quantization rates of $2,3,4$, and 6 bits/sample. Additionally, bistatic acquisitions with different quantization rates between master and slave SAR images have been generated. For example, 3 bits/sample for TSX has been combined with 2 bits/sample on TDX, and then 4 bits/sample 


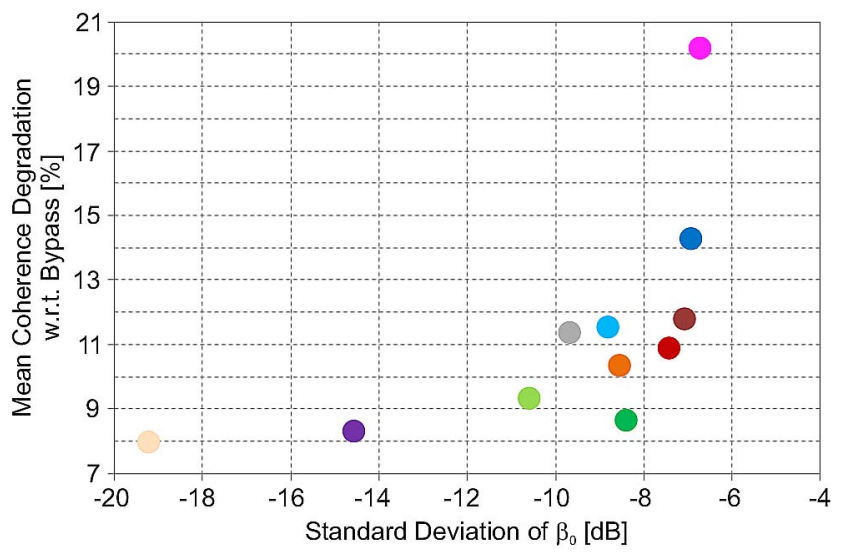

Fig. 9. Increase in coherence loss (for BAQ 8:2 with respect to the bypass case), due to inhomogeneity in the backscattered response, represented by the standard deviation of the measured radar brightness $\beta_{0}$ over a test site. For the interpretation of the colors, refer to the legend in Fig. 8.

on TSX and 3 bits/sample on TDX. By this, the noninteger quantization rates of 2.5 and 3.5 bits/sample, respectively, can be implemented and investigated. On the right-hand side of Fig. 8, the coherence degradation with respect to the bypass case is depicted. Each curve describes the performance of one acquisition, which has been compressed to different BAQ rates. In particular, an average coherence degradation of about $1 \%$ and $3.5 \%$ is noticed by using the rates of 4 and 3 bits/sample for both satellites, respectively, which are the nominal configurations that have been used for the first global DEM acquisition of TanDEM-X. The black bars represent the average and the standard deviation of the estimations for each BAQ rate, and a good agreement with the theoretic prediction is observed, marked by the green lines for the case of 2,3, and 4 bits [2]. It can be noticed that the standard deviation of the estimates increases when reducing the quantization rate. Again, an explanation of this effect is given by looking at the backscatter distribution within the scene. In Fig. 9, the coherence degradation for the case of 2 bits/sample (for which the dispersion is most evident) is plotted along the standard deviation of the measured radar brightness $\beta_{0}$, which gives information about the degree of homogeneity in the backscatter response of the imaged area. The observed quantization decorrelation is approximately $8 \%$ for flat and homogeneous areas with standard deviations smaller than $-14 \mathrm{~dB}$, such as the Taklamakan desert (China) and the salt lake of Uyuni (Bolivia), depicted in flesh tone and violet, respectively. On the other hand, a quantization decorrelation from $14 \%$ up to $20 \%$ is observed for the urban areas of Las Vegas, NV, USA, and Mexico City, Mexico, marked in blue and pink, respectively. Here, the backscatter distribution is very inhomogeneous (showing high standard deviations above $-7 \mathrm{~dB}$ ). Moreover, over the urban areas, the performance is further degraded due to the presence of additional geometrical distortions, such as multiple reflections, which increase the noise in the interferometric phase (see also next section). Low scattering suppression effects represent therefore an additional nonlinear and signal-dependent error, which vitiates the hypothesis of additive independent Gaussian noise for quantization errors and needs to be taken into account when defining resource-allocation strategies for future SAR missions.

\section{Interferometric Phase Error}

The error affecting the interferometric phase is directly related to the coherence and to the equivalent number of looks $N_{l}$ employed within the multilooking process [2], [20]. For this analysis, interferograms originated from different compression rates have been obtained by using the experimental TanDEM-X processor (TAXI), developed at DLR [21]. The interferometric azimuth and ground-range resolution is about $12 \mathrm{~m}$, corresponding to $N_{l}$ values typically between 16 and 32 . The impact of raw data quantization on the interferometric phase has been evaluated by comparing, for a single data take, the noncompressed interferograms $\varphi_{\text {bypass }}$ with the ones generated by different BAQ rates $\varphi_{n}$

$$
\Delta \varphi_{n}=\varphi_{\text {bypass }}-\varphi_{n}
$$

where $n$ indicates the used compression rate (in bits/sample). The differential interferogram $\Delta \varphi_{n}$ is nominally confined in the interval $[-2 \pi, 2 \pi]$. However, the maximum real phase error achievable is equal to $\pm \pi$, and all possible values outside the interval $[-\pi, \pi]$ are wrapped around the corresponding bound, i.e.,

$$
\Delta \varphi_{n}: \pm \pi \pm \epsilon \equiv \mp \pi \pm \epsilon \quad \forall \epsilon \in[0, \pi] .
$$

Taking into account the above equivalence, the phase error due to quantization for the case of $n$ bits/sample may be finally expressed as

$$
\Delta \varphi_{\text {quant }, n}= \begin{cases}\Delta \varphi_{n}, & \text { if }\left|\Delta \varphi_{n}\right| \leq \pi \\ -\operatorname{sign}\left(\Delta \varphi_{n}\right) \cdot\left(2 \pi-\left|\Delta \varphi_{n}\right|\right), & \text { if }\left|\Delta \varphi_{n}\right|>\pi\end{cases}
$$

In general, $\Delta \varphi_{\text {quant }, n}$ has zero mean, independent of the quantization rate employed. On the other hand, its standard deviation gives information about the dispersion of the phase errors and has therefore been chosen as a quality parameter for performance assessment. The increase in the interferometric phase errors due to quantization is shown in Fig. 10 on the left-hand side. Each value represents the standard deviation of $\Delta \varphi_{\text {quant }, n}$ for each compression rate with reference to the bypass case. For this analysis, the test sites $1,5,6,8$, and 11 of Table II have been investigated. For the case of $n=3 \mathrm{bits} / \mathrm{sample}$, which is typically selected for nominal TanDEM-X acquisitions, phase errors between $5^{\circ}$ until about $22^{\circ}$ are observed for the (flat and homogeneous) salt lake of Uyuni and the urban area of Mexico City, respectively. It is worth restating that the interferograms used for comparison have been generated from the same original raw data, i.e., they differ only in the quantization rate employed for compression. Therefore, the observed phase error degradation is solely due to an increase in the quantization noise as all other error contributions, such as limited SNR or volume scattering, affect the data in the same way (for a given test site). On the right-hand side of Fig. 10, the standard deviation of the difference between the radar brightness $\beta_{0}$ (of the master acquisition) generated from BAQ bypass and that from different BAQ rates is depicted for the same test areas. The highest deviation is observed for the urban area of Mexico City, which 

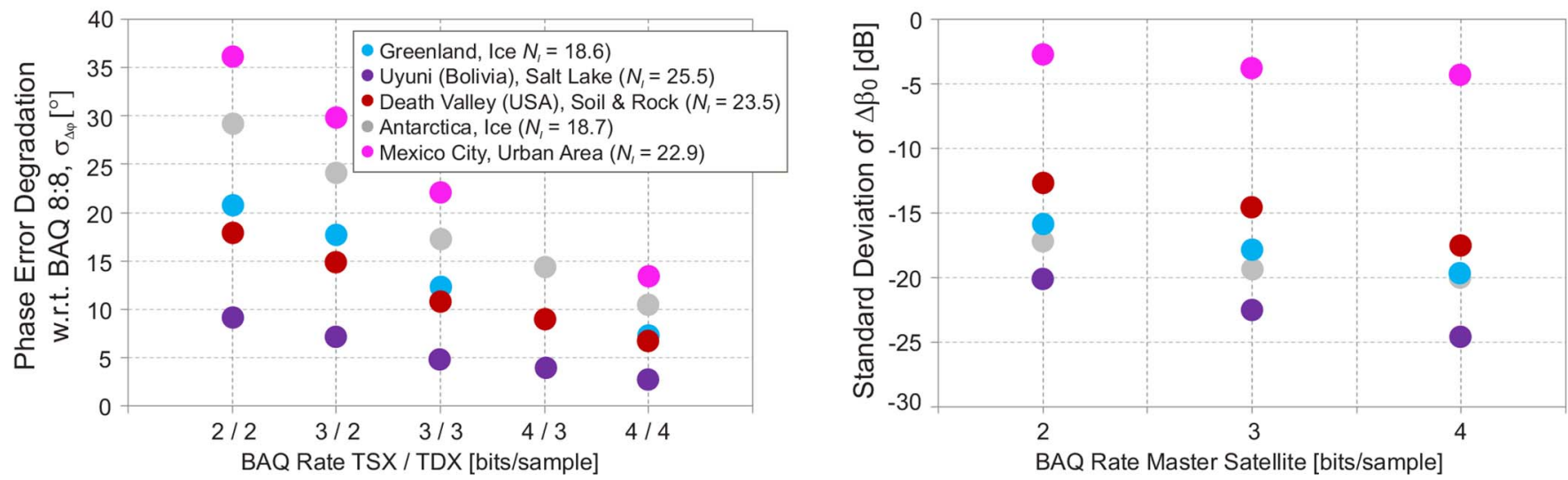

Fig. 10. (Left) Increase in the interferometric phase error due to quantization. Each value represents the standard deviation of the differential interferogram for each compression rate with reference to the bypass case [ $\Delta \varphi_{\text {quant, } n}$ in (7)], for a given acquisition. The total equivalent number of looks $N_{l}$ for each test site is specified in the legend. (Right) Increase in the errors introduced in the SAR amplitude due to quantization. Each value represents the standard deviation of the radar brightness difference $\Delta \beta_{0}$ (of the master acquisition) for different compression rates with reference to the bypass case. For the interpretation of the colors, refer to the legend on the left-hand side.
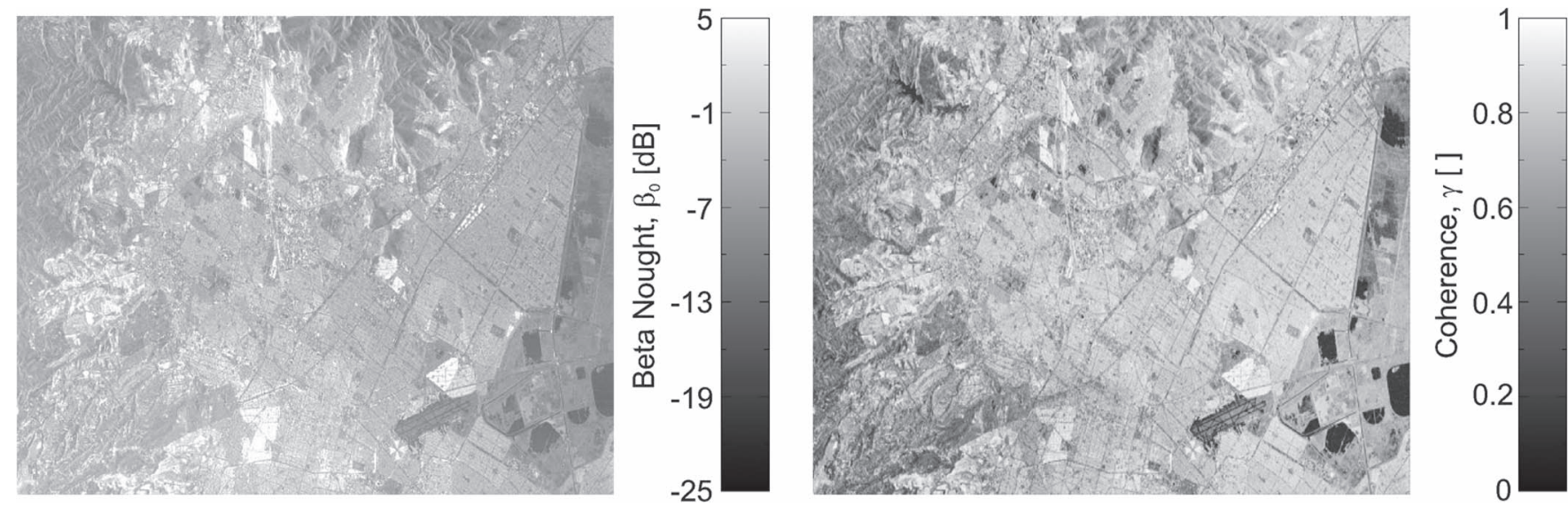

Fig. 11. (Left) Radar backscatter map of the urban area of Mexico City. (Right) Corresponding coherence map. The area is characterized by a very high dynamic range of backscatter due to the dominant presence of man-made structures and rugged topography.

is characterized by a very high dynamic range of backscatter due to the dominant presence of man-made structures, as well as of rugged topography, as shown in Fig. 11, where the amplitude and coherence maps prior to quantization are depicted on the left-hand and right-hand sides, respectively. The absolute value of the phase error for the case of $n=$ 2 bits/sample $\left[\left|\Delta \varphi_{\text {quant, } 2}\right|\right.$ in (7)] is shown on the left-hand side of Fig. 12, and the phase error over the SNR is given on the right-hand side of the figure. ${ }^{1}$ The red line shows the standard deviation of the phase error distributions as a function of the SNR. It can be noticed that higher phase errors are located in areas of lower backscatter. This is due, first of all, to the fact that low backscatter areas are more strongly affected by the nonlinear distortions introduced by the Cartesian I/Q quantization. In particular, for low amplitude signals, only few discrete phase values are obtainable at the output of the quantizer, whereas for high amplitude signals, more phase values are available; therefore, smaller errors, resulting from different quantization settings, are observed in the interferometric phase

\footnotetext{
${ }^{1}$ For a detailed description about the procedure for estimating the SNR from TSX and TDX data, and a quantitative assessment on the interferometric performance of TDX, refer to [19].
}

[22]. In addition to that, low scattering suppression effects (see Section II-B) also degrade the performance. On the other hand, for very high SNRs, the phase errors due to quantization asymptotically tend to zero, showing that an increase in the compression rate has, over such areas, a negligible impact on the absolute performance degradation.

Furthermore, it is of some interest to evaluate the impact of raw data quantization on the overall end-to-end interferometric performance. The interferometric phase errors can be estimated by means of the well-established theoretical model proposed in [20] for the statistical determination of the interferometric quality descriptors. According to the model, the interferometric phase error $\varphi$ is estimated directly from the coherence $\gamma$ and the independent number of looks $N_{l}$ employed within the multilooking process. The probability density function of the phase difference between two interferometric SAR channels is given by [20]

$$
\begin{aligned}
p_{\varphi}(\varphi)=\frac{\Gamma\left(N_{l}+\frac{1}{2}\right)\left(1-\gamma^{2}\right)^{N_{l}} \gamma \cos \varphi}{2 \sqrt{\pi} \Gamma\left(N_{l}\right)\left(1-\gamma^{2} \cos ^{2} \varphi\right)^{N_{l}+\frac{1}{2}}} \\
\quad+\frac{\left(1-\gamma^{2}\right)^{N_{l}}}{2 \pi} F\left(N_{l}, 1 ; \frac{1}{2} ; \gamma^{2} \cos ^{2} \varphi\right)
\end{aligned}
$$



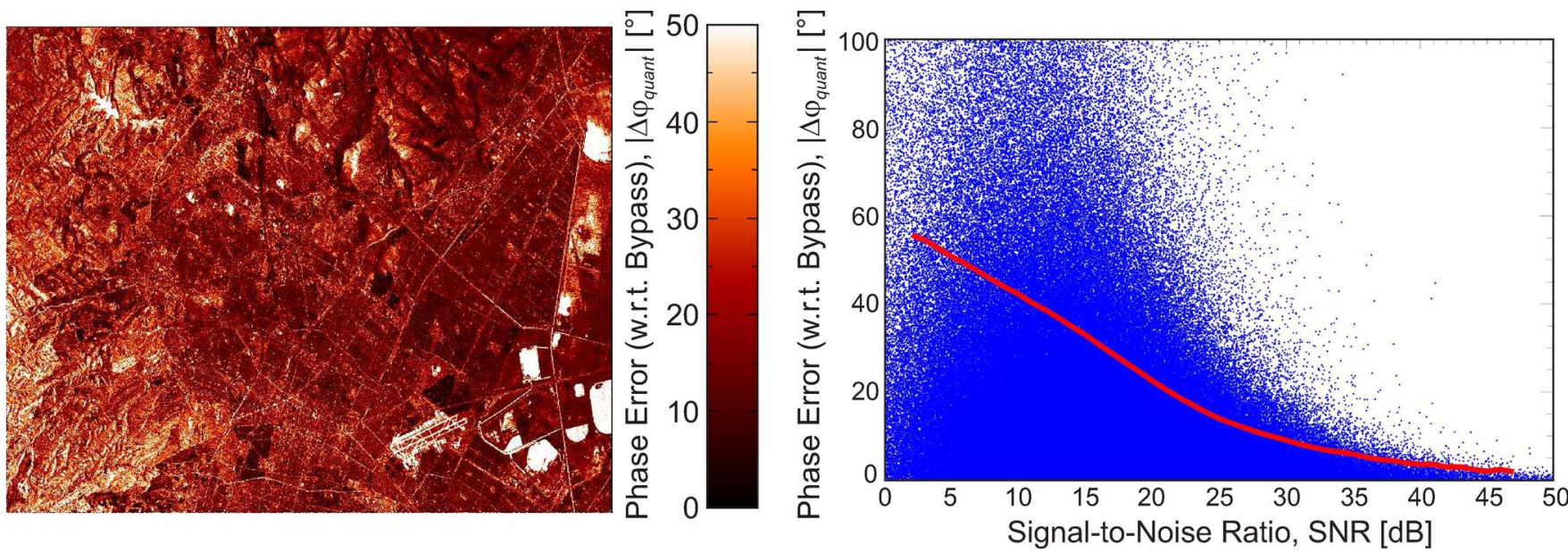

Fig. 12. (Left) Phase error map $\Delta \varphi_{\text {quant, } n}$ of the urban area of Mexico City, obtained as in (7), for $n=2$ bits/sample. (Right) Phase error over SNR, derived from the map on the left. The red line shows the standard deviation of the phase error distributions, as a function of the SNR. Higher phase errors are located in areas of lower backscatter (and vice versa) as a consequence of nonlinearities introduced by the quantization, together with the occurrence of low scattering suppression effects.

where $\Gamma$ is the gamma function, and $F$ is the hypergeometric function [23]. In general, if the coherence is lower, then the standard deviation of the phase error is higher, i.e.,

$$
\sigma_{\varphi}=\sqrt{\int_{-\pi}^{\pi} \varphi^{2} p_{\varphi}(\varphi) \mathrm{d} \varphi} .
$$

Hence, from each value of a coherence map originated with $n$ bits/sample, the corresponding phase error $\sigma_{\varphi_{n}}$ is estimated according to (9). The performance degradation due to quantization may be finally expressed by the phase error ratio, i.e.,

$$
\Delta \varphi_{\text {ratio, } n}=\frac{\sigma_{\varphi_{n}}}{\sigma_{\varphi_{\text {bypass }}}}
$$

and is depicted in Fig. 13 for different compression rates. Each value represents the ratio between the mean values of the corresponding phase error maps $\left\langle\sigma_{\varphi_{n}}\right\rangle /\left\langle\sigma_{\varphi_{\text {bypass }}}\right\rangle$. For the Antarctica test site (gray circles), a small phase error degradation lower than $20 \%$ is observed. The same area shows poor coherence of about 0.55 (see left-hand side of Fig. 8), which is mainly due to the occurrence of SNR and volume decorrelation effects. Therefore, the impact of quantization errors on the overall performance decreases. On the other hand, for the urban area of Mexico City, a degradation of up to $70 \%$ is observed. The corresponding phase error ratio map for the case of $n=2$ bits/sample [calculated according to (10)] is shown on the left-hand side of Fig. 14, and the phase error ratio over the coherence prior to quantization is depicted on the right-hand side of the figure. The red line shows the mean value of the phase error ratio distributions as a function of the coherence. As explained previously, over low-coherence areas, other decorrelation sources, such as limited SNR and/or volume scattering, become dominant. There, phase errors due to quantization are indeed high, but their relative impact on the overall performance is smaller (compare the left-hand side of this figure also with Figs. 11 and 12).

Looking at the local scale, an example of low scattering suppression caused by raw data quantization in presence of in-

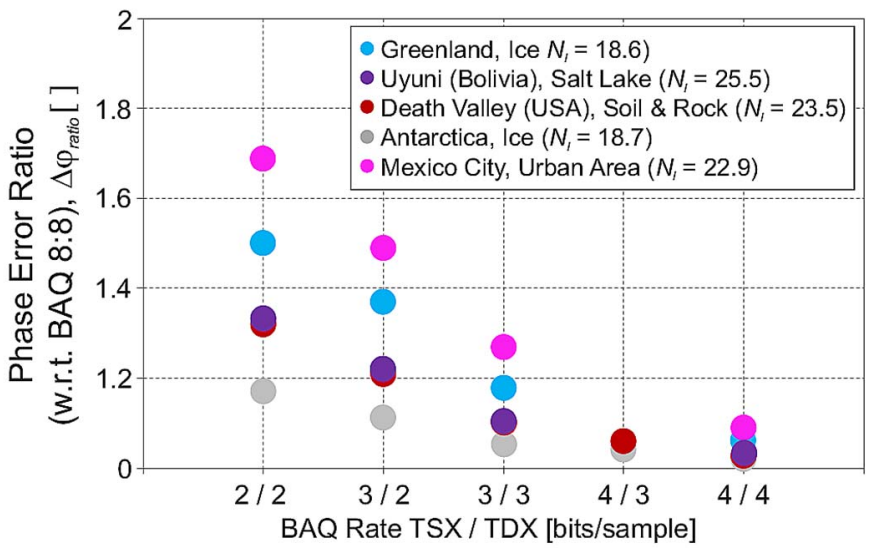

Fig. 13. Phase error ratio $\Delta \varphi_{\text {ratio, } n}$ for different compression rates with reference to the bypass case [estimated according to (10)]. Each value represents the ratio between the mean values of the corresponding phase error maps. The total equivalent number of looks $N_{l}$ for each test site is specified in the legend.

homogeneity in the backscatter distribution is given in Fig. 15. On the left-hand side, the radar brightness (beta-nought, $\beta_{0}$ ) for an area located in the Death Valley, CA, USA, is depicted. The region extends by about $5 \mathrm{~km}$ in the azimuth and range directions. The backscattered signal shows a discontinuity along the range direction, due to a change of the land cover characteristics from rocky terrain to sparsely vegetated terrain. For the present analysis, the subset marked in pink has been considered, and the measured radar brightness and the corresponding interferometric phase error, calculated as in (7), have been evaluated. The resulting phase error profiles (their absolute value has been considered, i.e., $\left.\left|\Delta \varphi_{\text {quant }, n}\right|\right)$ are depicted on the right-hand side of Fig. 15 for different compression rates. In correspondence to a sudden decrease of about $6 \mathrm{~dB}$ in the backscatter response, a clear jump in the interferometric phase error is visible. Moreover, if the bits employed for quantization are fewer, then the degradation in the phase error due to the reduced compression rate is higher (i.e., the "height" of the jump). For the case of 4 bits/sample (blue line in Fig. 15), the phase error goes from about $2^{\circ}$ in the high backscatter area to $4^{\circ}$ in the low backscatter area. Therefore, an additional degradation of 

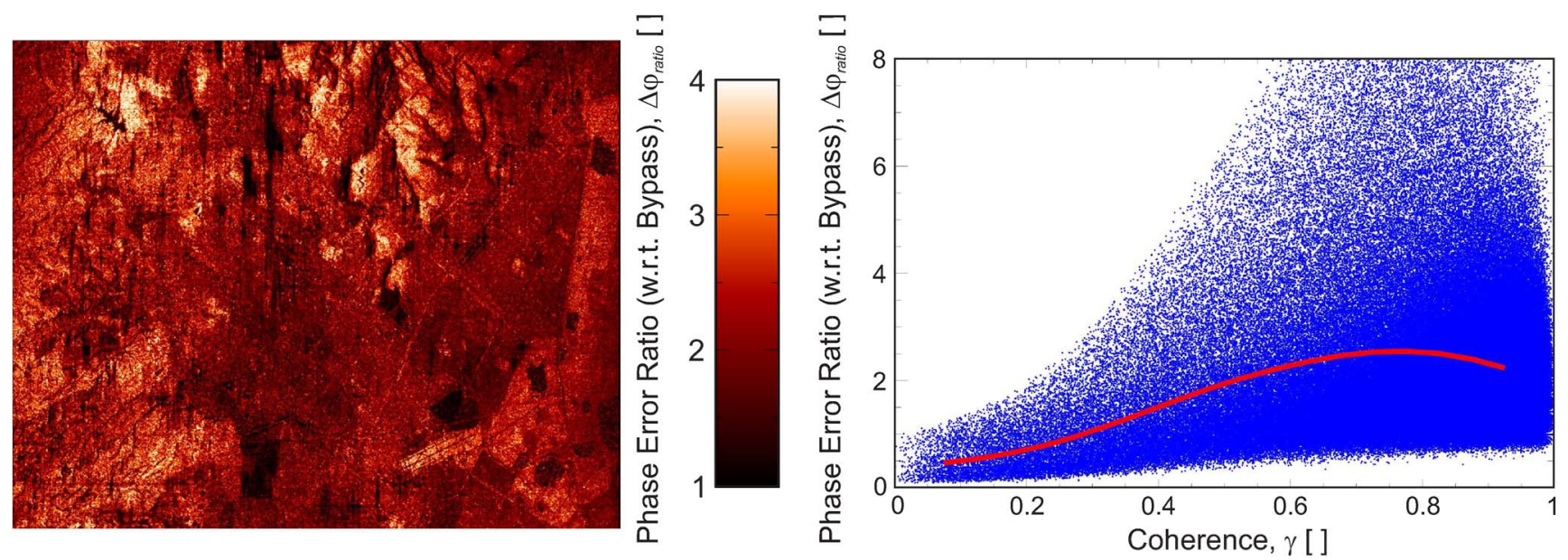

Fig. 14. (Left) Phase error ratio map $\Delta \varphi_{\text {ratio, } n}$ of the urban area of Mexico City, obtained as in (10), for $n=2$ bits/sample. (Right) Phase error ratio over coherence prior to quantization, derived from the map on the left. The red line shows the mean value of the phase error ratio distributions, as a function of the coherence. Over low-backscatter/coherence areas, other phase error sources (such as limited SNR and/or volume scattering) become dominant, and quantization errors have a smaller impact on the overall performance (compare also with Figs. 11 and 12).
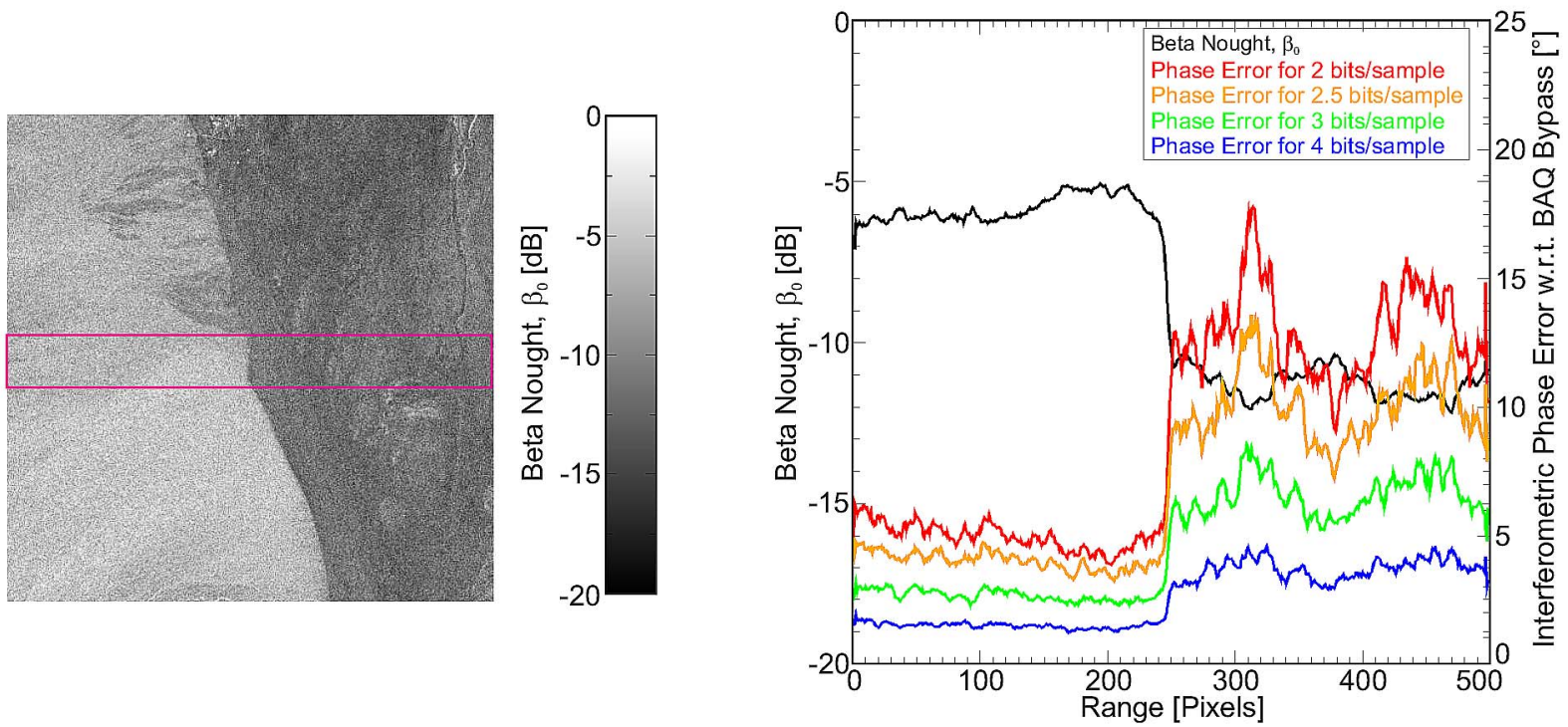

Fig. 15. (Left) Radar backscatter map $\beta_{0}$ of an area located in the Death Valley, CA, USA. (Right) Over the area highlighted in pink, the beta-nought and interferometric phase error profiles for different quantization rates are sketched. A notable degradation of the phase is observed in case of sudden variations in the backscatter response, as a consequence of the low scattering suppression.

about $2^{\circ}$ due to the low scattering suppression is observed. On the other hand, for the case of 2 bits/sample (red line in Fig. 15), the phase error goes from $5^{\circ}$ in the high backscatter region to approximately $13^{\circ}$ in the low backscatter one: The low scattering suppression effect for the case of 2 bits/sample causes therefore an additional degradation of about $8^{\circ}$. In correspondence to the low backscatter area, it can be noticed that the error profiles are very sensitive to the backscatter behavior and look almost "complementary" to it, showing higher values exactly where the corresponding $\beta_{0}$ becomes lower, and this effect is more visible if fewer bits are employed for compression. However, one has to consider that the phase errors are of course already higher in the low backscatter area; therefore, the additional effect from quantization may be less severe than it may appear from the results shown here. On the other hand, only slight dependence on backscatter of the phase noise (more or less constant along range) is observed for all compression rates within the slice showing higher backscatter (left part of the image). The strong dependence of the interferometric phase errors due to quantization on backscatter needs to be strictly taken into account for the performance budget definition since errors in the interferogram affect both the relative height accuracy (as discussed in the Section III-D), and the phase unwrapping quality, which represents a critical step for the DEM generation. Indeed, for the global DEM produced by TDX, at least two interferometric acquisitions are required in order to meet the mission specification [14] and to ensure, in most cases, a sufficient phase unwrapping quality [24].

\section{Relative Height Error}

Once the interferometric phase error has been estimated, the relative height accuracy of a DEM can be derived as

$$
\Delta h=\mathrm{HoA} \cdot(\Delta \varphi / 2 \pi)
$$




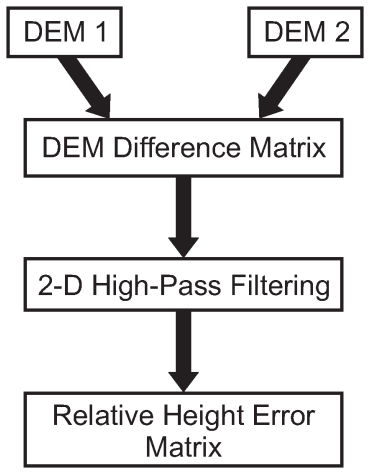

Fig. 16. Workflow for relative height error analysis from repeat-pass DEMs.

and is defined as the uncertainty on a height estimation due to noise-like disturbance contributions. HoA stands for height of ambiguity, which represents the height difference corresponding to a complete $2 \pi$ cycle of the interferometric phase and, in turn, is defined as

$$
\mathrm{HoA}=\frac{\lambda r \sin \left(\theta_{i}\right)}{\mathrm{B}_{\perp}}
$$

with $\lambda$ being the radar wavelength, $r$ the slant range, $\theta_{i}$ the incidence angle, and $B_{\perp}$ the baseline perpendicular to the line of sight. For the first global acquisition of TanDEM-X, the HoA was typically between 45 and $60 \mathrm{~m}$, ensuring good unwrapping quality over most land types. For the second global DEM coverage, larger baselines have been considered (HoA of about $35 \mathrm{~m}$ ). The combination of at least two acquisitions by means of multibaseline phase unwrapping algorithms [24] will allow to fully meet the mission requirements [2]. The estimation of the point-to-point relative height error requires the computation of the probability density function obtained by evaluating the difference between two random variables, each of them describing the fluctuation of the height estimate within one DEM. From real data, the point-to-point relative height accuracy can be estimated by evaluating the difference between repeated DEM acquisitions with identical imaging geometry and configuration parameters, each of them affected by independent noise components [25], as shown in Fig. 16. A high-pass filtering is then performed to erase slowly varying error sources, such as baseline or attitude uncertainties, which will be removed during the final DEM calibration process [26], [27]. Due to a baseline estimation error on the order of millimeters, the resulting DEM horizontal localization accuracy, for typical TanDEM-X baselines and incidence angles, is on the order of few meters [28]. Together with the dominant noise-like contribution, additional error sources may be due to phase unwrapping errors, as well as temporal changes in the scene occurring between the two acquisitions. For the present analysis, we have considered repeated bistatic TDX acquisitions commanded with BAQ bypass. The $90 \%$ point-to-point relative height error, as required by TanDEM-X mission specifications [2], [29], has been evaluated for the test areas listed in Table III (corresponding to the sites $1,3,5,8$, and 11 of Table II). It is computed as the $90 \%$ percentile of the absolute value of the height error matrix evaluated as in Fig. 16. The relative height error, $\Delta h_{90 \%}$, resulting from different compression rates, is shown on the left-
TABLE III

Test Sites for Relative Height Error Analysis. For Each Test Site, Repeated Bistatic TDX ACQuisitions HaVE BeEN COMMANDED WITH BAQ BYPASS AND WITH IDENTICAL IMAGING GEOMETRY

\begin{tabular}{|l|l|l|l|}
\hline Test Site & $1^{\text {st }}$ Pass & $2^{\text {nd }}$ Pass & HoA \\
\hline Salar de Uyuni (Bolivia) & $2010-11-16$ & $2012-06-10$ & $36 \mathrm{~m}$ \\
\hline Mexico City & $2012-02-07$ & $2012-02-29$ & $67 \mathrm{~m}$ \\
\hline Greenland & $2012-01-15$ & $2012-02-06$ & $81 \mathrm{~m}$ \\
\hline Amazon Forest (Brazil) & $2012-01-17$ & $2012-02-19$ & $84 \mathrm{~m}$ \\
\hline Death Valley (USA) & $2010-11-24$ & $2010-12-05$ & $150 \mathrm{~m}$ \\
\hline
\end{tabular}

hand side of Fig. 17. Each value represents the 90\% pointto-point relative height error obtained from two repeat-pass DEM acquisitions, and for each height error estimation, both DEMs result from data takes that all use the same compression rates. According to (11), the relative height accuracy is directly proportional to the HoA. Indeed, looking again at the plot on the left-hand side of Fig. 17, it can be noticed that the highest height error values are obtained for the test area of Death Valley (from 6 to $8 \mathrm{~m}$ ), acquired with a HoA of about $150 \mathrm{~m}$. On the other hand, the height errors estimated over the salt lake of Uyuni are of about four times smaller (approximately $2 \mathrm{~m}$ ), which is consistent with the ratio of the heights of ambiguity of the corresponding DEM acquisitions $(150 \mathrm{~m} / 36 \mathrm{~m})$. Therefore, in order to consistently compare the performance between the different test areas, normalization with respect to the HoA characterizing each acquisition pair is needed. We may define the normalized relative height error degradation, for a single data take, as the difference between the $90 \%$ point-to-point height error derived from noncompressed DEMs, and the ones originated from different BAQ rates (see $n$ bits/sample), i.e.,

$$
\Delta\left(\Delta h_{90 \%, n}\right)_{\mathrm{HoA}}=\frac{1}{\mathrm{HoA}}\left(\Delta h_{90 \%, \text { bypass }}-\Delta h_{90 \%, n}\right) .
$$

The resulting normalized height error degradation, expressed in the percentage of the HoA, is depicted on the right-hand side of Fig. 17 for different compression rates. It has to be noticed that, for a given test site, the DEMs used for comparison have been created from the same original raw data, i.e., they differ only in the quantization rate employed for compression. Therefore, the observed height accuracy degradation represents the contribution to the total relative height error in the DEM, which is produced uniquely by the quantization process. Once again, it can be verified that the performance degrades more severely for the urban area of Mexico City, for which a degradation of up to $4 \%$ of the HoA is observed. If considering typical HoAs employed for TDX nominal acquisitions (between 30 to $50 \mathrm{~m}$ ), the use of 2 bits/sample for both coverage areas would in this case have resulted in an increase between 1.2 and $2 \mathrm{~m}$ in terms of relative height accuracy, ultimately leading to a probable violation of the DEM specifications. As aforementioned, for most of the global DEM acquisitions of TanDEM-X, BAQ 8:3 (mainly) and BAQ 8:4 are employed, which grant a mean additional error of about $30 \mathrm{~cm}$ with respect to the uncompressed data (and below $60 \mathrm{~cm}$ for the worst case).

The present results have been also validated with the wellestablished theoretical model proposed in [20], which has been referred to in Section III-C. According to the model, 


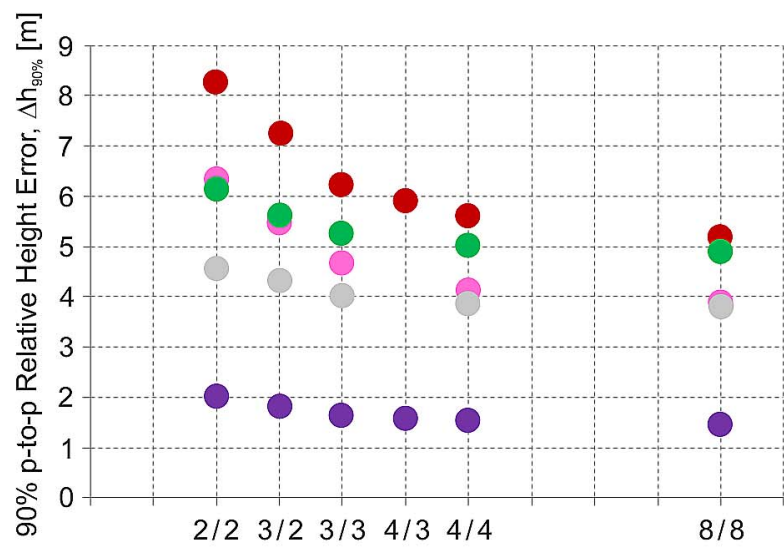

BAQ Rate TSX/TDX used for each DEM [bits/sample]

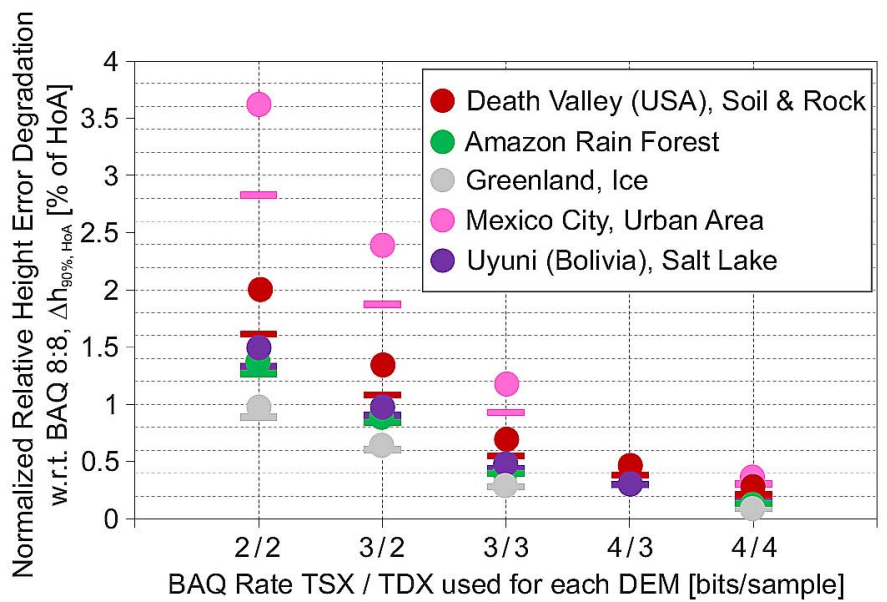

Fig. 17. (Left) $90 \%$ point-to-point relative height error as a function of the compression rate, evaluated as shown in Fig. 16, for the repeated acquisitions listed in Table II. (Right) Normalized degradation of the relative height error with respect to the bypass case, expressed as fraction of HoA [see also (13)]. The horizontal lines represent the corresponding height error degradation obtained from the theoretical model in [20]. For a given test site, the DEMs used for comparison are

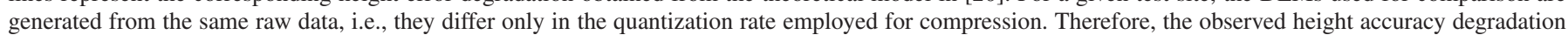
represents the contribution to the total relative height error in the DEM solely due to quantization.

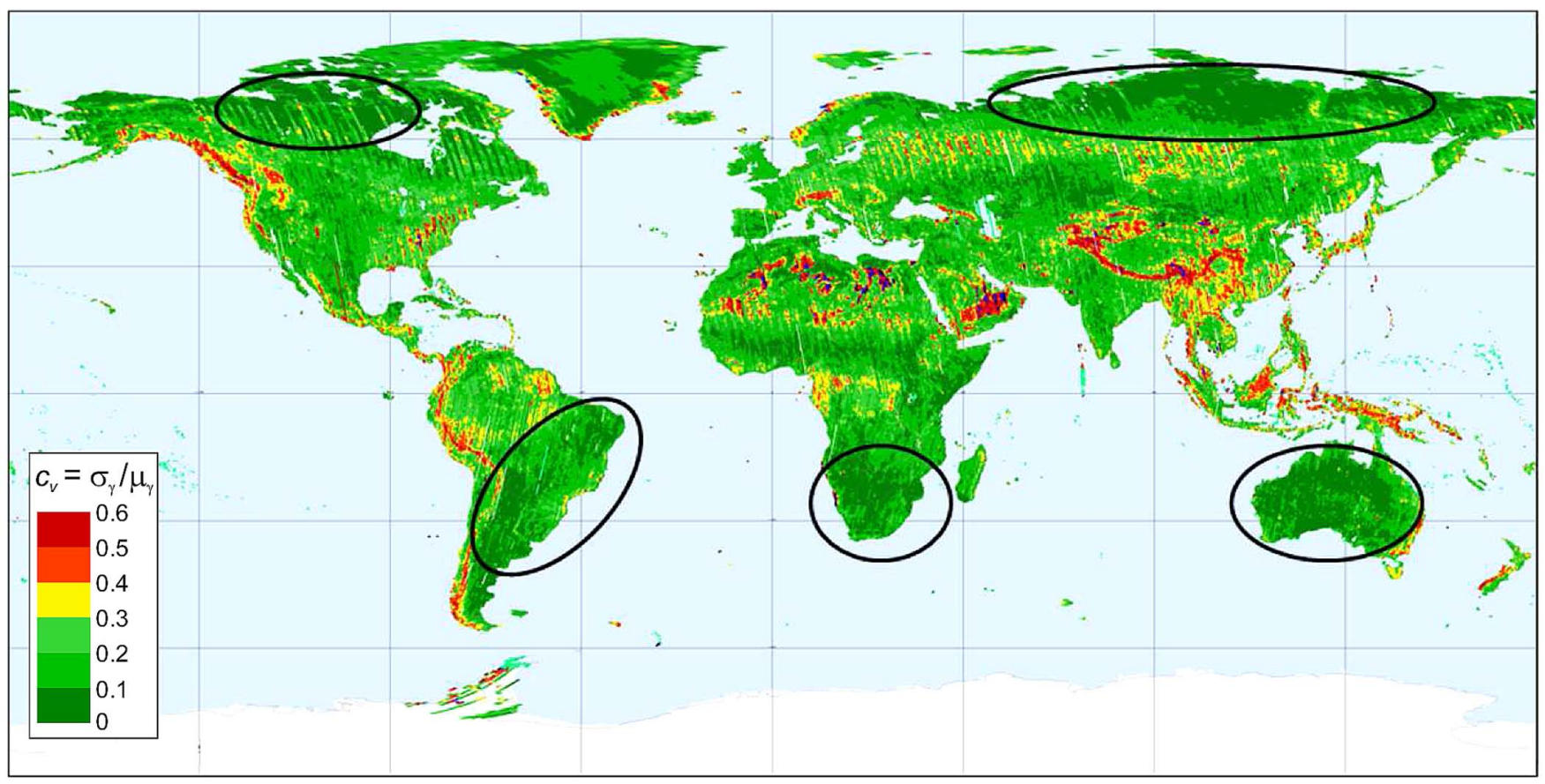

Fig. 18. Variation coefficient $c_{v}$ of the interferometric coherence for the first global DEM acquisition. The Antarctic region has been already acquired but not yet processed. For each scene $(50 \mathrm{~km} \times 30 \mathrm{~km}), c_{v}$ is calculated as the ratio of the standard deviation and the mean coherence, according to (14). The main regions considered for resource optimization for the second global acquisition are outlined with black circles. Here, homogeneous backscatter distribution and very good performance $(\gamma>0.8)$ are usually observed. On the other hand, yellow and red areas require additional acquisitions with optimized imaging geometry to further improve the overall DEM performance.

the interferometric phase error $\varphi$ can be estimated directly from the coherence $\gamma$ and the independent number of looks $N_{l}$ employed within the multilooking process. In particular, for each pixel of a processed interferogram, the $90 \%$ relative height error $\Delta h_{90 \%}$ is estimated, and the mean value per scene is then considered. The relative height error degradation derived from the model proposed in [20] is given by the horizontal bars on the right-hand side of Fig. 17. Good agreement between the two approaches can be verified for the sites of "Amazon Rain Forest," "Greenland," and "Uyuni." These areas are characterized by flat and regular height profiles, with an almost error-free phase unwrapping process. On the other hand, for the "Death Valley" and "Mexico City" test sites, the theoretical model underestimates the height error degradation derived from the data. As aforementioned, both test areas are characterized by an inhomogeneous backscatter distribution, together with rugged topography, where low scattering suppression effects cause additional performance degradation (see also Section III-A). For the described reasons, phase unwrapping errors occur more often (and most likely in the case where fewer bits are employed for quantization), leading in turn to incorrect height estimates in the resulting DEM. Such errors, as well as 
possible temporal changes in the scene occurring between the two repeated acquisitions, are not taken into account in the theoretical model used for comparison, which explains the observed discrepancy.

\section{Resource-Allocation Strategy for the SECOND GLOBAL DEM ACQUISITION}

Up to July 2013, TanDEM-X has completed the acquisition of two global DEMs in bistatic configuration. For nominal mission operation, mainly BAQ 8:3 for both satellites has been employed. Indeed, TSX and TDX have a relatively limited downlink capacity, which is due to an average contact time with the ground station network of about $10 \mathrm{~min} /$ orbit at a total net data rate of about $260 \mathrm{Mbits} / \mathrm{s}$, as indicated in Table I (the downlink time has to be shared among the two spacecraft since the close satellite formation does not permit the simultaneous downlink of the data). Considering nominal acquisition parameters, this implies an allowed time for bistatic data takes of about $180 \mathrm{~s} /$ orbit, for the case of a quantization with 3 bits/ sample [2]. Based on the analyses presented in this paper, the strategy for optimizing the resource allocation for the second global acquisition of TDX has been consequently adapted. Areas showing very good performance and homogeneous backscatter characteristics have been acquired with reduced compression rates. The variation coefficient of the interferometric coherence for the first global DEM coverage is given in Fig. 18. The variation coefficient is defined as the ratio of the standard deviation $\sigma$ and the mean $\mu$ of the coherence $\gamma$, i.e.,

$$
c_{v}=\frac{\sigma_{\gamma}}{\mu_{\gamma}} .
$$

It is calculated for each processed scene, which extends for an azimuth length of about $50 \mathrm{~km}$, and a range width of about $30 \mathrm{~km}$. Usually, high variation in the amplitude is associated with high variation in the coherence distribution. On the other hand, for high coherence, smaller variation has been typically observed $\left(c_{v}<0.2\right)$ for the most part of natural land areas. The main regions, which have been selected for resource optimization, are highlighted in the black circles. Here, high coherence (usually bigger than 0.8 ), homogeneous backscatter distribution, and good unwrapping quality are observed. In particular, quantization rates of 2 and 2.5 bits/sample (the latter obtained using 3 bits/sample on one satellite and 2 bits/sample on the other satellite) have been employed over such selected areas. The mean BAQ rate was then reduced from 3.09 bits/sample for the first global DEM acquisition to 2.95 bits/sample for the second one, and a consequent reduction in terms of mean data rate of about 5\% was gained, without affecting the overall mission performance (for many of these areas, a single acquisition is already sufficient to fulfill the relative height error mission requirements [19], [30]). On the other hand, the resulting free orbit usage (about $125 \mathrm{~s}$ more per day) has been exploited for reacquisition with optimized imaging geometry of areas affected by poor performance [31], [32], such as forest areas and difficult terrain (depicted in yellow and red in Fig. 18) to improve their final DEM quality [33], [34].

\section{CONCLUSION}

In this paper, we have presented the effects of raw data quantization on TanDEM-X bistatic data. Special experimental data takes were acquired with 8 bits/sample (i.e., without BAQ compression). On ground, all available quantization rates have been synthetically applied to the SAR raw data providing multiple data sets per satellite stream. Reprocessing with the interferometric chain was performed, even combining mixed data rates; as an example, 2 bits/sample from one satellite data and $3 \mathrm{bits} / \mathrm{sample}$ from the other satellite data result in an equivalent compression rate of 2.5 bits/sample. By this, a dedicated comparison with the original data was possible, isolating the quantization effects from other error sources. Key parameters in determining SAR and interferometric performance have been evaluated over test areas, showing different land cover types and topography characteristics. The radiometric sensitivity of a radar system (the NESZ) is severely affected by quantization, and a degradation of about 4 to $6 \mathrm{~dB}$ for the highest (i.e., 2-bit) compression rate with respect to the bypass case is shown. Quantization effects on the interferometric coherence are strongly dependent on the backscatter distribution of the imaged scene (low scattering suppression), and the observed decorrelation for the highest (i.e., 2-bit) compression rate varies between $8 \%$ for flat and homogeneous areas, and $20 \%$ for irregular regions, such as urban areas. Consistent results have been observed in the interferometric phase errors, as well as in the relative height accuracy of the DEM. In particular, it could be verified that, for typical TanDEM-X acquisition configurations, the employment of BAQ 8:2 for both coverage areas could have resulted in increased height errors, which in our analyses range from $0.5 \mathrm{~m}$ to $1.8 \mathrm{~m}$, leading in many areas to a violation of the DEM specifications. Therefore, for the first global DEM acquisition of TDX, mainly 3 bits/sample on both satellites are employed, which grant an acceptable performance degradation and, at the same time, a sufficient compression ratio in consideration of the nominal mission duration. Based on the presented analyses, an optimization of the resource-allocation strategy for the second global DEM acquisition of TanDEM-X has been carried out. Acquisitions over areas showing very good performance and homogeneous backscatter distribution have been commanded with reduced quantization rates of 2 and $2.5 \mathrm{bits} / \mathrm{sample}$. On the other hand, the resulting free onboard resources could be exploited for reacquisition of areas affected by poor performance to further improve the global DEM performance.

Looking at present and next-generation spaceborne SAR missions, an increasingly huge volume of onboard data is going to be demanded, which implies, from mission design, harder requirements in terms of onboard memory and downlink capacity. In this scenario, SAR raw data quantization represents an aspect of primary importance since the data rate employed for raw data digitization defines the amount of data to be stored and transmitted to the ground, and at the same time, it directly affects the performance of the SAR products. By exploiting the state-of-the-art quantization algorithms for SAR systems (the idea of mixed quantization rates in TDX has already progressed in terms of a new quantization switching scheme for future SAR 
systems [8]), the results presented in this paper can be therefore combined with the high-resolution and precise knowledge of the Earth's topography and backscatter characteristics produced by the TDX global data set [35]-[37], in order to provide a helpful tool for performance budget definition and optimization of the resource-allocation strategies for future SAR missions.

\section{ACKNOWLEDGMENT}

The authors would like to thank the anonymous reviewers for their valuable suggestions, P. Rizzoli and M. Bachmann of DLR-HR for their help and contribution, and S. Kerkhoff (DLR-IMF) and R. Reissig (DLR-DFD) for the processing of the experimental data.

\section{REFERENCES}

[1] M. Werner, "Shuttle Radar Topography Mission (SRTM): Mission overview," J. Telecomm. (Frequenz), vol. 55, no. 3, pp. 75-79, Mar. 2001

[2] G. Krieger et al., "TanDEM-X: A satellite formation for high-resolution SAR interferometry," IEEE Trans. Geosci. Remote Sens., vol. 45, no. 11, pp. 3317-3341, Nov. 2007.

[3] M. Zink, G. Krieger, H. Fiedler, I. Hajnsek, and A. Moreira, "The TanDEM-X mission concept," in Proc. EUSAR, Friedrichshafen, Germany, Jun. 2008, pp. 1-4.

[4] A. Moreira et al., "Tandem-L: A mission proposal for monitoring dynamic earth processes," in Proc. Int. Geosci. Remote Sens. Symp., Vancouver, BC, Canada, Jul. 2011, pp. 1385-1388.

[5] G. Krieger, I. Hajnsek, K. Papathanassiou, M. Younis, and A. Moreira, "Interferometric Synthetic Aperture Radar (SAR) missions employing formation flying," Proc IEEE, vol. 98, no. 5, pp. 816-843, May 2010.

[6] D. Lancashire, B. Barnes, and S. Udall, "Block adaptive quantization," U.S. Patent US 6255 987, Jul. 3, 2001. [Online]. Available: http://www. patentlens.net/patentlens/patent/US6255987/

[7] R. Kwok and W. T. K. Johnson, "Block adaptive quantization of Magellan SAR data," IEEE Geosci. Remote Sens. Lett., vol. 27, no. 4, pp. 375-383, Jul. 1989.

[8] M. Martone, B. Bräutigam, and G. Krieger, "Azimuth-Switched Quantization for SAR systems and performance analysis on TanDEM-X data," IEEE Geosci. Remote Sens. Lett., vol. 11, no. 1, pp. 181-185, Jan. 2014.

[9] T. Algra, "Data compression for operational SAR missions using entropyconstrained block adaptive quantization," in Proc. Int. Geosci. Remote Sens. Symp., 2002, pp. 1135-1138.

[10] E. Attema et al., "Flexible dynamic block adaptive quantization for Sentinel-1 SAR missions," IEEE Geosci. Remote Sens. Lett., vol. 7, no. 4, pp. 766-770, Oct. 2010.

[11] P. Guccione and A. Monti Guarnieri, "A space adaptive quantizer for spaceborne SAR," IEEE Trans. Geosci. Remote Sens., vol. 49, no. 10, pp. 3564-3573, Oct. 2011.

[12] J. Mittermayer, M. Younis, R. Metzig, S. Wollstadt, and J. MárquezMartínez, "TerraSAR-X system performance characterization and verification," IEEE Trans. Geosci. Remote Sens., vol. 48, no. 2, pp. 660-676, Feb. 2010

[13] M. Younis et al., "Determining the optimum compromise between SAR data compression and radiometric performance-An approach based on the analysis of TerraSAR-X data," in Proc. Int. Geosci. Remote Sens. Symp., Boston, MA, USA, Jul. 2008, pp. 107-110.

[14] S. Huber, M. Younis, and G. Krieger, "The TanDEM-X mission: Overview and interferometric performance," Int. J. Microw. Wireless Technol., vol. 2, no. 3/4, pp. 379-389, Jul. 2010.

[15] T. Fritz et al., "Interferometric processing of TanDEM-X data," in Proc. Int. Geosci. Remote Sens. Symp., Vancouver, BC, Canada, Jul. 2011, pp. 2428-2431.

[16] P. J. Curlander and R. N. McDonough, Synthetic Aperture Radar Systems and Signal Processing. New York, NY, USA: Wiley, 1991.

[17] T. Kraus, D. Schrank, P. Rizzoli, and B. Bräutigam, "In-orbit SAR performance of TerraSAR-X and TanDEM-X satellites," in Proc. URSI, Garmisch-Partenkirchen, Germany, Mar. 2011, pp. 1-6.
[18] M. Schwerdt, J. H. Gonzalez, M. Bachmann, and D. Schrank, "Monostatic calibration of both TanDEM-X satellites," in Proc. Int. Geosci. Remote Sens. Symp., Honolulu, HI, Jul. 2010, pp. 2636-2639.

[19] M. Martone et al., "Coherence evaluation of TanDEM-X interferometric data," ISPRS J. Photogramm. Remote Sens., vol. 73, pp. 21-29, Sep. 2012.

[20] J.-S. Lee, K. W. Hoppel, S. A. Mango, and A. R. Miller, "Intensity and phase statistics of multilook polarimetric and interferometric SAR imagery," IEEE Trans. Geosci. Remote Sens., vol. 32, no. 5, pp. 10171028, Sep. 1994.

[21] P. Prats et al., "TAXI: A versatile processing chain for experimental TanDEM-X product evaluation," in Proc. Int. Geosci. Remote Sens. Symp., Honolulu, HI, Jul. 2010, pp. 4059-4062.

[22] C. P. Niebla and G. Krieger, "Optimization of block-adaptive-quantization for sar raw data," Space Technol., vol. 23, no. 2/3, pp. 131-141, 2003.

[23] M. Abramowitz and I. Stegun, Handbook of Mathematical Functions. New York, NY, USA: Dover, 1965.

[24] M. Lachaise, M. Eineder, and T. Fritz, "The dual-baseline interferometric processing chain for the TanDEM-X mission," in Proc. Int. Geosci. Remote Sens. Symp., Munich, Germany, Jul. 2012, pp. 5562-5565.

[25] P. Rizzoli, B. Bräutigam, T. Kraus, M. Martone, and G. Krieger, "Relative height error analysis of TanDEM-X elevation data," ISPRS J. Photogramm. Remote Sens., vol. 73, pp. 30-38, Sep. 2012.

[26] A. Gruber, B. Wessel, M. Huber, and A. Roth, "Operational TanDEM-X DEM calibration and first validation results," ISPRS J. Photogramm. Remote Sens., vol. 73, pp. 39-49, Sep. 2012.

[27] M. Huber et al., "The global TanDEM-X DEM: Production status and first validation results," in Proc. 22th ISPRS Congr., Melbourne, VIC, Australia, Aug. 2012, pp. 45-50.

[28] J. H. González et al., "Tests of the TanDEM-X DEM calibration performance," in Proc. Int. Geosci. Remote Sens. Symp., Munich, Germany, Jul. 2012, pp. 303-306.

[29] B. Wessel, TanDEM-X Ground Segment-DEM Products Specification Document. [Online]. Available: http://tandemx-science.dlr.de/pdfs/ TD-GS-PS-0021_DEM-Product-Specification_v2.0.pdf

[30] B. Bräutigam et al., "TanDEM-X acquisition and quality overview with two global coverages," in Proc. Int. Geosci. Remote Sens. Symp., Melbourne, VIC, Australia, Jul. 2013, pp. 2958-2961.

[31] D. B. Tridon et al., "TanDEM-X: DEM acquisition in the third year era," in Proc. SFFMT, Munich, Germany, May 2013, pp. 1-26.

[32] C. Ortega-Míguez et al., "TanDEM-X acquisition planner," in Proc. EUSAR, Nuremberg, Germany, Apr. 2012, pp. 418-421.

[33] M. Martone, P. Rizzoli, B. Bräutigam, and G. Krieger, "First two years of TanDEM-X mission: Interferometric performance overview," Radio Sci., vol. 48, no. 5, pp. 617-627, Oct. 2013.

[34] G. Krieger et al., "TanDEM-X: A radar interferometer with two formation-flying satellites," Acta Astronautica, vol. 89, pp. 83-98, Sep. 2013.

[35] P. Rizzoli, B. Bräutigam, S. Wollstadt, and J. Mittermayer, "Radar backscatter mapping using TerraSAR-X," IEEE Trans. Geosci. Remote Sens., vol. 49, no. 10, pp. 3538-3547, Oct. 2011.

[36] P. Rizzoli and B. Bräutigam, "Radar backscatter characterization approach combining global TanDEM-X data," in Proc. Int. Geosci. Remote Sens. Symp., Munich, Germany, Jul. 2012, pp. 3305-3308.

[37] C. Gonzalez, B. Bräutigam, and P. Rizzoli, "SAR performance enhancements using radar backscatter map of TerraSAR-X," in Proc. EUSAR, Nuremberg, Germany, Apr. 2012, pp. 446-449.

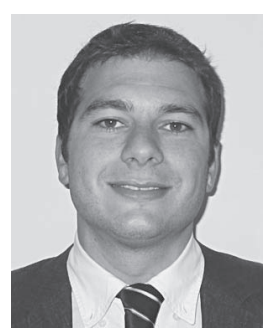

Michele Martone received the M.Sc. degree (with honors) in telecommunication engineering from the University of Naples Federico II, Naples, Italy, in 2009 , with a thesis on soil moisture estimation from polarimetric X-band SAR data, pursued at the Microwaves and Radar Institute, DLR, Wessling, Germany.

Since 2009, he has been with the Microwaves and Radar Institute, DLR, where he is currently working on SAR system design and performance analyses for the TerraSAR-X and TanDEM-X missions. 


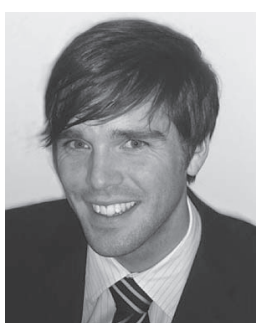

Benjamin Bräutigam received the Dipl.Ing. degree in electrical engineering from Karlsruhe Institute of Technology, Karlsruhe, Germany, in 2003.

In 2003, he was a Visiting Scientist with the NOAA Environmental Technology Laboratory, Boulder, CO, USA. Since 2004, he has been with the Microwaves and Radar Institute, DLR, Wessling, Germany. He was responsible for internal instrument calibration in spaceborne SAR projects such as TerraSAR-X, TanDEM-X, and Sentinel-1. Since 2008 , he has been the head of the research group for system performance, working on actual and future SAR missions. His main research interests include calibration and performance analysis of SAR systems.

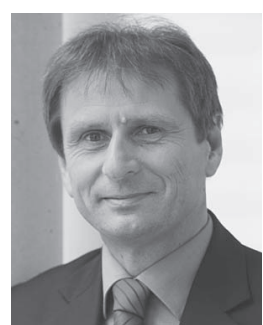

Gerhard Krieger (M'04-SM'09-F'13) received the Dipl.-Ing. (M.S.) and Dr.-Ing. (Ph.D.) degrees (with honors) in electrical and communication engineering from the Technical University of Munich, Munich, Germany, in 1992 and 1999, respectively.

From 1992 to 1999, he was with Ludwig Maximilian University of Munich, Munich, where he conducted multidisciplinary research on neuronal modeling and nonlinear information processing in biological and technical vision systems. Since 1999 , he has been with the Microwaves and Radar Institute, DLR, Wessling, Germany, where he developed signal and image processing algorithms for a novel forward-looking radar system employing digital beamforming on reception. From 2001 to 2007, he led the New SAR Missions Group, which pioneered the development of advanced bistatic and multistatic radar systems as exemplified by the TanDEM-X, as well as innovative multichannel SAR techniques and algorithms for high-resolution wide-swath SAR imaging. Since 2008, he has been the Head of the new Radar Concepts Department, Microwaves and Radar Institute, DLR. He is a Visiting Lecturer with Friedrich Alexander University, Erlangen, Germany, and is the author or coauthor of 62 peer-reviewed journal papers, seven invited book chapters, about 300 conference papers, and more than ten patents. His current research interests include the development of multichannel radar techniques and algorithms for innovative multiple-input-multiple-output SAR systems, the demonstration of novel interferometric and tomographic Earth observation applications, and the conceptual design of advanced bistatic and multistatic radar missions.

Dr. Krieger has been serving as an Associate Editor for the IEEE TRANSACTIONS ON GEOSCIENCE AND REMOTE SENSING since 2012. He received several national and international awards, including the W.R.G. Baker Prize Paper Award from the IEEE Board of Directors and the Transactions Prize Paper Award of the IEEE Geoscience and Remote Sensing Society. In 2012, he and his colleagues were nominated for the German President's Award for Technology and Innovation. 